\title{
Many Sectors Meet More Skills: Intersectoral Linkages and the Skill Bias of Technology
}

\author{
Nico Voigtländer* \\ UCLA \\ First draft: August 2007 \\ This draft: May 2009
}

\begin{abstract}
While intermediate inputs account for more than half of a final product's value, intersectoral linkages have been ignored as a source of skill bias. Previous empirical studies have investigated skill demand at the worker-, firm-, and sector-level. This paper extends the standard skill-biased technical change (SBTC) framework, introducing skill complementarity via input-output linkages. This generates a multiplier effect that magnifies small sector-level skill bias into a large aggregate impact on skill demand. We construct a proxy for the skill bias embedded in each sector's intermediates: Input skill intensity. This variable correlates strongly with the skill share employed in final production - a novel stylized fact that points towards technology-skill complementarity across sectors. Together with input-output linkages, the observed complementarity reinforces skill demand along the production chain. The effect is large, accounting for about one third of the observed skill upgrading in U.S. manufacturing over the period 1967-92.
\end{abstract}

JEL: J24, J31, O14, O15, O33, C67

Keywords: Skill-Biased Technical Change, Intermediate Linkages, Multiplier, Input-Output, Complementarity

\footnotetext{
*UCLA Anderson School of Management, 110 Westwood Plaza, Los Angeles, CA 90095; nico.v@ anderson.ucla.edu. I thank Fernando Broner, Paco Buera, Rob Feenstra, Gino Gancia, Yuriy Gorodnichenko, Pierre-Olivier Gourinchas, Chad Jones, Alexander Ludwig, Lee Ohanian, Giovanni Peri, Torsten Persson, David Romer, Jaume Ventura, Fabrizio Zilibotti, and seminar participants at UC Berkeley, CEMFI Madrid, Federal Reserve Board, IIES Stockholm, Northwestern University, UC Davis, UCLA, UCSC, and Universitat Pompeu Fabra for helpful comments. I am indebted to Paula Bustos, Antonio Ciccone, and Joachim Voth for invaluable discussions. Nathan Nunn kindly shared his data on product differentiation.
} 


\section{Introduction}

As the supply of skilled workers has risen, so has the skill premium. A wealth of studies following Katz and Murphy (1992) documents a substantial increase in the demand for skilled labor over the last decades. The full magnitude of this effect, however, has not yet been explained. The usual suspects behind rising skill premia - international trade, information technology, and innovation - can account for some, but not all of the observed rise in skill demand. Much of the literature has focused on skill-biased technical change (SBTC) - a shift in production technologies that favors skilled labor. Empirical studies have investigated SBTC at the worker-, firm-, and sector-level. Linkages across sectors have been ignored so far, despite the fact that more than half of a final product's value is embedded in intermediates.

This paper extends the standard SBTC framework. Instead of one representative firm it features many sectors that purchase each other's products as intermediate inputs. The skill bias of technology is not solely determined within sectors, but also has an intersectoral dimension. Skill-intensive intermediates require skills in their further processing or their integration into final products. Therefore, SBTC in one sector can increase skill demand in many other sectors, which delivers a multiplier that augments sector-level SBTC into larger aggregate skill bias. This can explain why within-sector studies fail to account for the full scope of aggregate SBTC. For example, the invention and improvement of the transistor affected skill demand within and outside its sector of origin, the electronic components industry. Within this industry, the transistor enabled the production of more refined electronic parts, engineered by highly skilled workers. These innovative electronic components eventually became fundamental intermediate inputs for a large variety of other sectors, including computers, communication equipment, and controlling devices, where their integration went hand in hand with skill upgrading.

Our stylized model predicts that sectors using skill-intensive intermediates employ a higher proportion of skilled workers in final production. To measure the former, we calculate input skill intensity - the weighted average share of skilled workers employed in intermediate production. We construct this measure by matching input-output tables with workforce data for 4-digit U.S. manufacturing sectors. ${ }^{1}$ Figure 1 presents the result for 1992. It shows a strong positive correlation between input skill intensity and the share of skilled workers in final production. This is a novel stylized fact. In the empirical analysis, we construct a panel for 358 U.S. manufacturing sectors in 5-year intervals between 1967 and 1992 - the period for which coherent input-output data are available. The correlation is stable over time, and is robust to the inclusion of a large number of additional controls. ${ }^{2}$ The strong positive correlation of skilled labor shares along the production chain provides empirical support for an intersectoral dimension of SBTC.

\footnotetext{
${ }^{1}$ In the empirical analysis, input skill intensity is the weighted average share of white-collar workers employed in the production of a sector's intermediate inputs. White-collar (non-production) workers - including personnel engaged in supervision, installation and servicing, professional, technological, and administrative - have been widely used to proxy for skilled labor. See in particular Berman, Bound, and Griliches (1994).

${ }^{2}$ These controls include sectoral fixed effects, time dummies, as well as various measures proposed in the wage inequality literature: capital intensity, shares of computer and high-tech capital, R\&D intensity, and outsourcing. We also exclude inputs from similar industries in the calculation of input skill intensity in order to address the concern that common trends drive the observed correlation.
} 


\section{[Insert Figure 1 here]}

In the framework introduced here, inputs from upstream sectors are not only 'intermediate' in the standard semi-manufactured sense, but also 'intermediaries' that transmit skill requirements across industries. This implies an intersectoral technology-skill complementarity (ITSC), which goes beyond the well-known within-sector complementarity between skills and technology. What is the channel through which ITSC works its wonders? We argue that product innovation is key. Skilled workers are not merely more productive, but are also good innovators, adapt better to technological change, and speed the process of technological diffusion (Nelson and Phelps, 1966; Bartel and Lichtenberg, 1987; Goldin and Katz, 1998; Doms, Dunne, and Troske, 1997). Because of this, an upstream supplier that employs highly educated workers will turn out innovative intermediates. These upstream product improvements induce innovation at the downstream level, which in turn increases downstream skill demand. ${ }^{3}$ Equally, a cutting-edge downstream firm demands innovative intermediate inputs. To supply these, upstream producers need highly skilled workers. Thus, whether innovation originates upstream or downstream is not crucial for our complementarity argument.

While this paper offers no direct proof that ITSC works through product innovation, we provide evidence that is consistent with this claim. The argument is based on the relationship between product innovation and differentiation. Differentiated goods can be refined more readily than homogenous ones. The presence of engineers contributes to the continuous improvement of electronic components. On the other hand, crude petroleum does not change, whether it is pumped out of the ground by laborers or university graduates. Therefore, differentiated inputs are more susceptive to 'skill embedding' - their product characteristics reflect the skill intensity, or complexity, of the underlying production process. In contrast, innovations in the production of homogenous inputs improve processes rather than products, and thus have little effect on downstream skill demand. ${ }^{4}$ Combining Rauch's (1999) classification of product differentiation with inputoutput tables, we construct a measure of input differentiation. We demonstrate that ITSC is increasing in the degree of input differentiation, and is close to zero for sectors that use mainly homogenous inputs. In other words, intersectoral skill complementarities are strong when differentiated intermediates like electronic components form the link. However, when linkages work through homogenous goods like crude oil, intermediate skill intensity does not matter for skill shares in final production.

Finally, we investigate the importance of ITSC. Its contribution is large, explaining up to one third of the increase in white-collar labor demand in U.S. manufacturing over the period 1967-92.5 To derive this number, we apply the Feenstra and Hanson (1999) approach, adding input skill intensity. Interestingly, ITSC is orthogonal to previously suggested explanations of increasing skill demand - it does not dilute the

\footnotetext{
${ }^{3}$ As Scherer (1982) for the United States and Pavitt (1984) for Great Britain show, product innovation in upstream sectors serves to improve productivity and quality of output in the buying industries.

${ }^{4}$ We provide evidence for this assertion, combining data on sectoral product and process innovation from Scherer (1982) with Rauch's (1999) classification of product differentiation. The constructed cross-section shows that product innovation is more pronounced in sectors that produce differentiated goods. Thus, downstream users of differentiated intermediates purchase relatively more embedded product innovation.

${ }^{5}$ This is similar to the contribution of IT capital and more than twice the one of outsourcing or R\&D.
} 
explanatory power of other variables.

This paper adds a novel angle to a large body of studies that seek to explain the remarkable increase in wage inequality in the United States starting in the 1960s. ${ }^{6}$ Existing work can explain some of the rising inequality, but falls short of accounting for all of it. The first prominent channel is trade and its effect on international patterns of specialization (e.g., Leamer, 1996; Wood, 1998). The between-component of trade - relocating production of low-skill-intensive industries to low-skill abundant countries - contributes little to the observed skill upgrading (Berman et al., 1994; Autor, Katz, and Krueger, 1998). Within-industry effects appear to be more important. To explain this observation, Feenstra and Hanson (1999) suggest outsourcing of low-skill intensive activities within firms or sectors. Their measure explains up to $15 \%$ of relative wage increases in U.S. manufacturing.

The second prominent channel is skill-biased technical change. Numerous studies conceptualize SBTC as a complementarity between capital (or technology) and skills, where computer-based information technologies (IT) play a central, although disputed role (DiNardo and Pischke, 1997; Card and DiNardo, 2002; Autor, Levy, and Murnane, 2003). So far, the empirical SBTC literature has treated technology-skill complementarities as a phenomenon within specific industries, within firms, and at the worker level. ${ }^{7}$ Computers and other high-tech capital have been shown to contribute about $1 / 3$ to the increase in white-collar labor demand in manufacturing (Feenstra and Hanson, 1999; Autor et al., 1998, 2003). ${ }^{8}$ The role of a broader complementarity between capital equipment and skilled labor has proved controversial. ${ }^{9} \mathrm{R} \& \mathrm{D}$ is another potential driver of SBTC. However, while several studies document significantly positive coefficients on R\&D intensity (Machin and van Reenen, 1998; Autor et al., 1998), the variable itself changes relatively little over time. We show below that rising R\&D intensity can account for about $5 \%$ of skill upgrading in U.S. manufacturing. Finally, Autor et al. (2008) demonstrate that falling minimum wages are unlikely to have played an important role for the secular rise in wage inequality, which revises earlier claims by Card and DiNardo (2002). Together, the previously suggested drivers of skill upgrading explain only about half of the

\footnotetext{
${ }^{6}$ For a recent review see Autor, Katz, and Kearney (2008), who also show that the growth of wage inequality is not an episodic event and provide new evidence showing that demand forces have played a key role in this process. Skill upgrading, i.e., a rise in skilled labor's share in employment and payroll, is also observed in other OECD countries (Machin and van Reenen, 1998; Berman, Bound, and Machin, 1998) as well as in developing countries (Pavcnik, 2003; Zhu, 2005). Acemoglu (1998, 2002a, 2007) provides a theoretical framework for factor-biased technological change.

${ }^{7}$ For industries, Berman et al. (1994) find that the rate of skill upgrading within U.S. manufacturing is strongly correlated with IT investment and R\&D; IT accounts for much of the demand shift towards skilled workers over the 1980s. This effect has been greater in more IT-intensive industries (Autor et al., 1998). Autor et al. (2003) argue that computer capital substitutes for 'routine tasks' while it complements more complex 'nonroutine' tasks performed by skilled workers. At the firm and plant level, Levy and Murnane (1996), Doms et al. (1997), and Bresnahan, Brynjolfsson, and Hitt (2002) use broad measures of technological progress and provide evidence for skill-favoring demand shifts. Finally, at the worker level, Krueger (1993) and Autor et al. (1998) document a strong positive correlation between wages and computer use. Epifani and Gancia (2006) point out scale increases as an additional channel for skill bias. See Bound and Johnson (1992) and Autor et al. (2008) for an assessment of alternative explanations for wage inequality. Katz and Autor (1999) and Sanders and ter Weel (2000) summarize the literature at the three levels of aggregation.

${ }^{8}$ These estimates are to be interpreted with caution, as they take correlation coefficients as causal effects. Autor et al. (2003) investigate computer-induced task shifts in all sectors of the U.S. economy. Their approach can explain up to sixty percent of the relative demand shift favoring college labor; half of this impact is due to task changes within nominally identical occupations. The remaining thirty percent between occupations are similar to Feenstra and Hanson's finding.

${ }^{9}$ This concept was first formalized by Griliches (1969). Krusell, Ohanian, Ríus-Rull, and Violante (2000) document an important contribution to skill upgrading, but Acemoglu (2002b) shows that their result disappears upon the inclusion of a linear time trend.
} 
overall magnitude. The results in this paper suggest that linkages and complementarities across sectors can explain much of the remainder.

There is an ample literature on input-output linkages, starting with the pioneering work of Leontief (1936) and Hirschman (1958). Recent studies have focused on the role of input-output multipliers in economic development. Ciccone (2002) shows that small increasing returns at the firm level can translate into large effects on aggregate income when industrialization goes hand in hand with the adoption of intermediate-input intensive technologies. Jones (2009) adds the role of input complementarity. Multipliers have also been used to explain the growth in the trade share of output, or the cyclical behavior of aggregate productivity. ${ }^{10}$ However, this paper is the first to investigate the role of intersectoral linkages for skill upgrading.

The rest of the paper is organized as follows. The next section introduces the framework of input-output linkages and relates it to skill complementarity across sectors. Section 3 presents a simple model that adds intermediate inputs to the standard SBTC framework. The section also derives three testable predictions. Section 4 describes the data and explains the construction of a novel variable - input skill intensity. Section 5 reports empirical results, documenting the intersectoral technology-skill complementarity, and confirms its robustness. In addition, we derive a regression from a labor-demand framework to estimate ITSC's contribution to skill upgrading. We address endogeneity issues by using a set of IV regressions and check instrument validity, applying weak instrument tests and overidentifying restrictions. Section 6 concludes.

\section{Framework: Intersectoral Linkages and Skill Complementarity}

This paper argues that intersectoral technology-skill complementarities can boost skill demand. However, linkages across industries alone need not imply connected skill requirements. What makes the proposed point plausible is innovation-skill complementarity within sectors, combined with innovation spillovers across sectors, through input-output linkages. Before formalizing the joint framework in a simple model, we briefly review these two concepts.

\section{Intermediate linkages and innovation spillovers}

Intermediate inputs account for a substantial share of overall costs - about 50\% according to U.S. inputoutput tables. The remaining costs include employee compensation (about 30\%) and payments to capital (about $16 \%) .{ }^{11}$ Studies of capital-skill complementarity therefore focus on a relatively small component of the final product's value. It is important to note that the approach in this paper is strictly separated from the capital-skill complementarity literature. By construction, intermediate linkages do not include investment

\footnotetext{
${ }^{10} \mathrm{Yi}$ (2003) shows that small decreases in tariff barriers multiply up to large trade increases when intermediates are traded several times during the production process. Basu (1995) argues that intermediate goods act as a multiplier for price stickiness, augmenting little firm-level rigidity to a large economy-wide price inflexibility.

${ }^{11}$ These two, together with the minor component 'Indirect business tax and nontax liability' make up value added. All percentage values are derived from the 1992 U.S. input-output table from the Bureau of Economic Analysis. The numbers are very similar in other years.
} 
(capital) goods.

There is substantial evidence for technological linkages across sectors. Scherer (1982) and Pavitt (1984) use patent data to track the flow of innovation across sectors. Both confirm the overall prevalence of product innovation, which accounts for 73.8 percent of total $R \& D$ outlays in the United States, and 75.3 percent in Great Britain. ${ }^{12}$ As Scherer (1982, p.227) emphasizes:

"If [a new product] is a producer good or intermediate sold externally, it serves to improve output/input relationships or the quality of output in the buying industries. With a new turbojet engine product, for example, the $R \& D$ is performed in the aircraft engine industry, but the productivity effect often shows up in lower energy consumption or faster, quieter, and more reliable operation of equipment used by the quite distinct airlines industry. [...] to assume that the productivity-enhancing effect occurs solely within the R\&D-performing industry [...] is more wrong than right, since three-fourths of all industrial R\&D is devoted to new or improved products, as distinguished from processes."

There is ample evidence for innovation spillovers from upstream suppliers to downstream final producers, via intermediate linkages. The channel also operates in the opposite direction. For example, Blalock and Gertler (2008) document vertical spillovers in the case of foreign investment in Indonesia: Subsidiaries of multinational enterprises provide technological knowledge to their local intermediate suppliers in order to reduce prices and increase competition in upstream markets. ${ }^{13}$

\section{Synthesis}

Within sectors, innovation goes hand in hand with skilled labor. ${ }^{14}$ In addition, much of the innovative activity creates new products that are used as intermediates in other sectors. So far, these two facts have been treated separately in the literature. Combining them yields an intersectoral technology-skill complementarity. The interactions of innovation and skills run in both directions, and across sectors, reinforcing one another. Individually and collectively, innovations in sectors related through input-output (I-O) linkages increase the relative demand for skilled labor $(H / L)$ as summarized below:

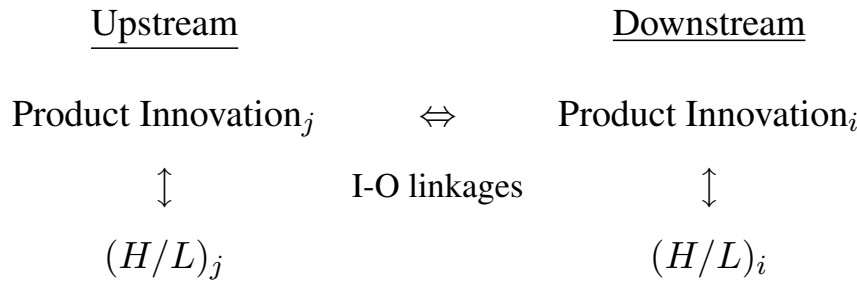

\footnotetext{
${ }^{12}$ In this context, product innovations are by definition used outside their sector of origin, i.e., they are passed to downstream sectors or consumers in the form of improved products. Scherer (1982) also provides evidence that most productivity benefits are realized by $R \& D$ using, rather than product R\&D-originating industries.

${ }^{13}$ For a theoretical framework see Rodríguez-Clare (1996). Keller (2004) and Koo (2005) summarize the literature on international and local technology spillovers.

${ }^{14}$ The same is true for the result of innovation: product quality. As Verhoogen (2008) shows, producing high-quality goods requires skilled workers.
} 
Closest in spirit to this paper are the complementarity frameworks proposed by Milgrom and Roberts (1990) and Bresnahan et al. (2002), where the adoption of IT, work organization, product innovation, and skill upgrading reinforce each other within, but not across firms.

\section{A Sketch Model}

The informal complementarity framework above postulates that skill bias in intermediate and final production are related through input-output linkages. To develop the formal implications of this presumption, we extend the standard SBTC framework. The standard setup has two types of labor in a CES production function, producing one final good. ${ }^{15}$ The sketch model presented here features $i=1, \ldots, N$ sectors, each producing a specific good $i$. Within each sector, a multiplicity of firms operates under perfect competition and constant returns. We focus on a representative firm for each sector $i$, making zero profits. Each good $i$ is used for final consumption and as intermediate input in sectors $j \neq i$. A Leontief technology for intermediates, with fixed input shares, ensures tractability of the model. We show in section 5.2 that the data broadly support constant shares of intermediates.

The economy is populated by $L$ low-skilled individuals, working in production, and $H$ high-skilled individuals that coordinate production and handle innovative intermediate inputs. Skill-biased technological change raises the productivity of type- $H$ workers relative to their type- $L$ counterparts. This relative skill bias is at the center of interest here. We therefore abstract from skill-neutral technological progress and focus on $H$-specific productivity. ${ }^{16}$ Following the discussion in section 2, we assume that skill-biased upstream technology can lead to downstream skill bias. ${ }^{17}$ Therefore, SBTC does not only affect skill demand within the originating sector $i$, but can also spill over to other sectors $j \neq i$ via the intermediate input channel. This implies intersectoral technology-skill complementarities that augment given within-sector SBTC to larger aggregate skill bias.

\section{Production}

A producer of good $i$ employs low-skilled labor $L_{i}$, high-skilled labor $H_{i}$, and an aggregate of intermediate inputs $\mathcal{X}_{i}$. Output of good $i$ is given by

$$
Y_{i}=\left[\gamma\left[A_{i} H_{i}\right]^{\frac{\epsilon-1}{\epsilon}}+(1-\gamma)\left[L_{i}\right]^{\frac{\epsilon-1}{\epsilon}}\right]^{\frac{\epsilon}{\epsilon-1} \alpha}\left(\mathcal{X}_{i}\right)^{1-\alpha}
$$

\footnotetext{
${ }^{15}$ See Card and DiNardo (2002) and Violante (2006) for a review of the standard SBTC framework.

${ }^{16}$ This restriction can be imposed without loss of generality. An extension with skill-neutral technical change delivers the same predictions for the relative skill bias.

${ }^{17}$ The model features a one-directional channel - from upstream to downstream. This restriction keeps the framework simple, while delivering the same qualitative results as a bi-directional setup. The model's predictions are thus to be interpreted as complementarities.
} 
where $\gamma$ is a technology parameter that indexes the share of work activities allocated to skilled labor, $\alpha$ is the share of aggregate labor in production, and $\epsilon$ is the elasticity of substitution between the two labor inputs. We assume $\epsilon>1$, such that $H_{i}$ and $L_{i}$ are substitutes. Finally, $A_{i}$ denotes the skill bias of technology in sector $i$, as specified in more detail below, and increases in $A_{i}$ correspond to SBTC.

Each sector $i$ uses the output from all sectors $j \neq i$ as intermediate inputs. To keep matters simple, we assume that intermediates enter final production (1) according to a Leontief technology:

$$
\mathcal{X}_{i}=\min _{j \neq i}\left\{\frac{1}{a_{i j}} X_{i j}\right\}
$$

where $X_{i j}$ is the amount of input $j$ used in the production of $\operatorname{good} i$, and $a_{i j} \in(0,1)$ is the corresponding input requirement. High $a_{i j}$ indicate that much of input $j$ is needed in the production of product $i$. Sectors do not use their own output as intermediate: $a_{i i}=0$, but use a positive amount of all others: $a_{i j}>0$, $\forall j \neq i ; a_{i j}$ is normalized such that $\sum_{j \neq i} a_{i j}=1$. Let $x_{i j} \equiv X_{i j} / a_{i j}$ denote the effective units of input $j$ in the production of $i$. When optimizing production, representative firm $i$ chooses the same amount of each effective input $j$, such that $x_{i j}=\bar{x}_{i}, \forall j$. Consequently,

$$
X_{i j}=a_{i j} \bar{x}_{i}
$$

where $\bar{x}_{i}$, is determined in the optimization of production (1), with $\mathcal{X}_{i}=\bar{x}_{i}$. A convenient feature is that $\bar{x}_{i}$ also gives the total amount of intermediates used, $\sum_{j \neq i} X_{i j}=\bar{x}_{i}$. Equation (3) implies that the share of input $j$ in sector $i$ is given by $X_{i j} / \sum_{j \neq i} X_{i j}=a_{i j}{ }^{18}$

Next, we turn to the skill bias of technology. $A_{i}$ is the relative productivity of skilled as compared to unskilled workers, or total skill bias in sector $i$. It consists of two components: $A_{i}=f\left(T_{i},\left\{A_{j}\right\}_{j \neq i}\right)$. First, $T_{i}$ denotes the skill bias of sector-specific technology. For example, the invention of semiconductors in the electronic components industry raised the productivity of electrical engineers within this industry. Purchases of computers or high-tech equipment in industry $i$ have a similar effect, reflected as increases in $T_{i}$. We assume that $T_{i}$ is exogenously given. Second, skill-biased technology in upstream production, $\left\{A_{j}\right\}_{j \neq i}$, also raises the productivity of skilled workers in sector $i$ that process them. Semiconductors affected skillspecific labor productivity not only in the electronics sector itself. A large variety of other sectors seized the opportunities embedded in the newly available electronic components. In those sectors, too, skilled labor became relatively more productive. Next, we specify how skill-biased technology in sectors $j \neq i, A_{j}$, contributes to skill bias in $i, A_{i}$. A natural way to weigh the various contributions is by input shares $a_{i j}$. Summing over all intermediates, we define input skill bias:

$$
\sigma_{i}=\sum_{j \neq i} a_{i j} A_{j}
$$

Thus, $\sigma_{i}$ represents the weighted average skill bias that is embedded in intermediates used by sector $i$. Using

\footnotetext{
${ }^{18}$ This refers to units of inputs. In the empirical analysis, $a_{i j}$ represents price-adjusted expenditure shares.
} 
this definition, we choose the functional form for the total skill bias in sector $i$ :

$$
A_{i}=T_{i} \sigma_{i}^{\phi_{i}}
$$

The parameter $\phi_{i} \in[0,1)$ indicates the strength of ITSC, i.e., how strongly upstream SBTC influences the skill bias in downstream sectors. This can vary across sectors. If $\phi_{i}>0$, the relative productivity of skilled labor in sector $i$ increases in input skill bias. On the other hand, if $\phi_{i}=0$ we are back to a standard SBTC setup, where total skill bias $A_{i}$ depends only on the within-sector component $T_{i}$.

\section{Optimization}

Firms take factor and goods prices as given and choose $L_{i}, H_{i}$, and $\bar{x}_{i}$ to maximize profits from production (1) subject to (2) - (4). $\mathcal{X}_{i}$ in (1) is replaced by $\bar{x}_{i}$ because of the Leontief technology related to intermediate inputs. The total cost of intermediates is $\sum_{j \neq i} p_{j} X_{i j}$, with $X_{i j}$ given by (3). A representative firm in sector $i$ optimizes

$$
\max _{\left\{L_{i}, H_{i}, \bar{x}_{i}\right\}} p_{i} Y_{i}-w_{L} L_{i}-w_{H} H_{i}-\sum_{j \neq i} p_{j} a_{i j} \bar{x}_{i}
$$

where $p_{i}$ is the price of good $i$. A convenient implication of the Leontief technology is that firms do not adjust intermediate input proportions $a_{i j}$ if upstream skill bias $A_{j}$ changes; that is, firms take $\sigma_{i}$ as given. Setting the ratio of the two labor types' marginal products equal to the ratio of their wages and rearranging yields the relative demand for skilled labor:

$$
\frac{H_{i}}{L_{i}}=\left(\frac{\gamma}{1-\gamma}\right)^{\epsilon}\left(T_{i} \sigma_{i}^{\phi_{i}}\right)^{\epsilon-1}\left(\frac{w_{L}}{w_{H}}\right)^{\epsilon}
$$

Relative skill demand is determined by the inverse skill premium and the parameter $\gamma$. Both are the same across sectors. In addition, within-sector skill bias $T_{i}$ and input skill bias $\sigma_{i}$ drive up skill demand. To close the model, we need to specify the demand side and market clearing conditions. These further steps are not crucial for the intuition; they are presented in Appendix A.1.

\section{A proxy for input skill bias}

In order to take the model to the data, we need an empirical measure of $\sigma_{i}$. We apply equations (5) and (7) to a sector $j \neq i$ and rearrange for the total skill bias in $j$ :

$$
A_{j}=\left(\frac{1-\gamma}{\gamma} \frac{w_{H}}{w_{L}}\right)^{\frac{\epsilon}{\epsilon-1}}\left(\frac{H_{j}}{L_{j}}\right)^{\frac{1}{\epsilon-1}}
$$


The term in the first parentheses is constant across sectors, and the second one is proportional to the share of skilled workers in $j, h_{j} \equiv H_{j} /\left(L_{j}+H_{j}\right) .{ }^{19}$ This leads to a proxy for input skill bias:

$$
\sigma_{i}=\sum_{j \neq i} a_{i j} A_{j} \sim \sum_{j \neq i} a_{i j} h_{j} \in[0,1]
$$

where the last term represents the weighted average share of skilled workers that produce sector $i$ 's intermediate inputs. We refer to this measure as input skill intensity. Section 5 describes its construction by combining input-output data with worker characteristics.

\section{The symmetric case and the multiplier effect}

The final theoretical step is to formally derive the multiplier of skill bias. For expositional reasons, we focus on the symmetric case of the model. This is sufficient to explain the main intuition, and is more readily compared to the standard SBTC framework. However, heterogeneity of sectors is important for testing the model's empirical predictions.

Definition 1 The symmetric case of the model is characterized by all sectors having the same within-sector skill bias, $T_{i}=T$, and the same input requirements, $a_{i j}=1 /(N-1), \forall j \neq i, \forall i$. In addition, the strength of ITSC is the same across sectors: $\phi_{i}=\phi, \forall i=1, \ldots, N$.

Symmetric within-sector skill bias and equal strength of ITSC in all sectors imply $\sigma_{i}=\sum_{j \neq i} a_{i j} A=$ $A, \forall i .^{20}$ Therefore, the total skill bias $A$ is symmetric and (5) simplifies to

$$
A=T^{1 /(1-\phi)}
$$

This equation describes the multiplier effect. To see how it works, we derive the skill premium at the aggregate level. Appendix A.1 shows that in the symmetric equilibrium the relative wage is given by

$$
\frac{w_{H}}{w_{L}}=\frac{\gamma}{1-\gamma}\left(T^{\frac{\epsilon-1}{\epsilon}}\right)^{1 /(1-\phi)}\left(\frac{L}{H}\right)^{\frac{1}{\epsilon}}
$$

The parameter $\phi$ can be interpreted as the average strength of ITSC in the economy. Note that if $\phi=0$, aggregate skill bias is equal to within-sector skill bias, which corresponds to the standard SBTC framework. A multiplicity of studies following Katz and Murphy (1992) estimate (11) in logs and capture aggregate skill bias by a time trend, commonly finding a large coefficient. However, as discussed above, within-sector drivers of skill demand (represented by $T_{i}$ ) alone cannot explain the full magnitude of the observed skill upgrading. The framework presented here can reconcile these findings. With $\phi>0$, intersectoral linkages deliver a multiplier effect. SBTC in one sector raises the skill bias in other sectors and eventually feeds back

\footnotetext{
${ }^{19}$ We use $h$ rather than $H / L$ because the former is bounded between zero and one such that the resulting proxy is more readily interpreted. None of the empirical results depend on this choice - the two measures are close to linearly related over the relevant range in the dataset, with percentiles $p_{1}(h)=0.093$ and $p_{99}(h)=0.634$.

${ }^{20}$ See Appendix A.1 for a proof.
} 
into the originating sector. This amplifies within-sector skill bias, as reflected by the exponent $1 /(1-\phi)$, which boosts aggregate skill demand. ${ }^{21}$

\section{Predictions of the model}

Recall that the main assumption in the model was that skill biased upstream technology can lead to downstream skill bias. It does so in sectors with $\phi_{i}>0$. Provided that this condition holds in a sufficiently large subset of sectors, the model implies the following three propositions that can be tested empirically.

P1. The proportion of skilled workers in sectors $i, h_{i}$, increases in within-sector skill bias $T_{i}$ and in input skill intensity $\sigma_{i}$. The latter is defined as the weighted average share of skilled workers employed in the production of sector $i$ 's intermediate inputs.

P2. The correlation between $h_{i}$ and $\sigma_{i}$ can vary by sector. It is the stronger the larger $\phi_{i}$, i.e., the larger the extent to which skill bias in upstream technology influences downstream skill bias.

P3. There is a multiplier that magnifies small within-sector SBTC to larger aggregate skill bias.

The first two propositions follow from (7), and the last one from (10). Testing P1 is straightforward, using controls for within-sector skill bias from the SBTC literature and constructing the new variable input skill intensity by combining input-output tables with data on worker characteristics. To test P2, we split the sample by the degree of input differentiation. The underlying idea is that skill biased innovation in upstream sectors influences downstream skill bias by changing the product that links the sectors. Differentiated intermediates are more amenable to product innovation than homogenous ones. Therefore, we expect a stronger ITSC when linkages involve more differentiated intermediates. Finally, to estimate the importance of the multiplier effect in P3, we ideally want a point estimate of $\phi$. However, this would require the functional forms - in particular (5) and (9) - to be correctly specified. Misspecification can cause parameter estimates to be inconsistent (e.g., White, 1982). In order to address this concern, we estimate a demand framework based on a translog cost function, which imposes few restrictions on the shape of the corresponding production function. The results show that ITSC can account for about one third of the observed increase in skill demand in U.S. manufacturing.

\section{Data}

This section describes the data that we use to test predictions P1-P3. Data on worker characteristics, wages, value of shipment, and real capital (equipment and structures) at the 4-digit SIC level are from the NBERCES Manufacturing Industry Database. These data are collected from various years of the Annual Survey

\footnotetext{
${ }^{21}$ The setup here is similar to Jones' (2009) model that delivers a multiplier for productivity differences. The multiplier channel, however, is different. In Jones' paper, higher intermediate productivity leads to more output, which feeds back into the production of intermediates. The share of intermediate goods in total revenue is therefore crucial for the size of the multiplier. In our approach, the intermediate input share in total output, $1-\alpha$, is not important for ITSC. What counts is the size of the parameter $\phi$, i.e., by how much skill biased innovation embedded in intermediates, $\sigma_{i}$, influences downstream skill bias, $A_{i}$. Linkages are only important for granting that sectors process each others' output. They are necessary, but not sufficient for a multiplier to exist.
} 
of Manufactures (ASM), and have been widely used to investigate the determinants of the rise in U.S. wage inequality. ${ }^{22}$ This database classifies employment in two broad categories: production and non-production workers. The former are 'workers engaged in fabricating, processing, assembling, inspecting, and other manufacturing', while the latter are 'personnel, including those engaged in supervision, installation and servicing of own product, sales, delivery, professional, technological, administrative, etc.' As noted by Berman et al. (1994), the production/non-production classification closely mirrors the distinction between blue- and white-collar occupations from the Current Population Survey, which in turn closely reflects educational levels as high school vs. college. In the following, we refer to non-production (white-collar) workers as high-skilled labor $H$ and to production (blue-collar) workers as low-skilled labor $L$.

The Bureau of Economic Analysis' (BEA) Input-Output Use Tables specify expenditures of each industry $i$ for intermediate inputs purchased from industry $j$. The BEA provides U.S. input-output (I-O) data at the 4-digit SIC level in 5-year periods between 1967 and 1992. For some sectors, the level of aggregation or coverage changes over time. We account for this by aggregating sectors, and match the resulting I-O panel to the ASM's 1987 SIC classification. ${ }^{23}$ This yields a panel of 358 manufacturing industries over the period 1967-1992. For each industry, the panel contains production and non-production employment and wages, value of shipment with the corresponding deflator $(1987=1)$, real capital equipment and structures (all from the ASM), and the purchases of industry $i$ from sector $j$ (from the BEA I-O data). All figures provided in the BEA's I-O Use Tables are in nominal dollars. We use the shipment deflators provided by the ASM to calculate, for every manufacturing industry $i$, its price-adjusted expenditures for inputs from each manufacturing industry $j$ in year $t, X_{i j}^{t}{ }^{24}$

\section{Constructing input skill intensity}

To construct input skill intensity $\sigma_{i t}$, we first obtain intermediate input shares from the price-adjusted I-O expenditure data $X_{i j}^{t}$. Let $X_{i}^{t}=\sum_{j \neq i} X_{i j}^{t}$ represent total (price-adjusted) expenditures for manufacturing inputs purchased by industry $i$ outside the same industry in period $t$. The time-varying price-adjusted intermediate input shares are then given by $a_{i j}^{t}=X_{i j}^{t} / X_{i}^{t}$. These are broadly stable over time. Spearman's rank correlation coefficients for $a_{i j}^{t}$ are highly significant and range between 0.45 (for $a_{i j}^{1967}, a_{i j}^{1992}$ ) and 0.92 (for $a_{i j}^{1977}, a_{i j}^{1982}$ ). The same is true for pairwise correlation coefficients, ranging between 0.72 and 0.93 . Remaining fluctuations over the six benchmark years appear to be noise. ${ }^{25}$ We use average price-adjusted

\footnotetext{
${ }^{22}$ Examples include Berman et al. (1994), Autor et al. (1998), and Feenstra and Hanson (1999). See Bartelsman and Grey (1996) for a documentation of these data.

${ }^{23}$ For example, paper mills (SIC 2621) and paperboard mills (SIC 2631) are available separately in the I-O data until 1982, but aggregated from 1987 on. We treat these data as one sector, 'paper and paperboard mills' over the full sample period. Detailed sector correspondences are available upon request.

${ }^{24}$ This is slightly abusing notation; in the model $X_{i j}$ represents physical input quantity.

${ }^{25}$ For example, in 1967 'Paperboard containers and boxes' accounted for 3.4\% of the manufacturing inputs in the 'Chocolate and cacao products' sector. This number more than quadrupled 5 years later $(13.4 \%)$, stabilizing at $6.5 \%$ thereafter until 1992 . There is no reason to believe that the changing proportion reflects physical input shares. Measurement error as well as fluctuations in relative input prices, imperfectly corrected by the deflators, appear to be reasonable explanations.
} 
input shares $\bar{a}_{i j}=\sum_{t=67}^{92} a_{i j}^{t}$ between 1967 and 1992 as a baseline. ${ }^{26}$ Input skill intensity is then defined as

$$
\sigma_{i}^{t}=\sum_{j \neq i} \bar{a}_{i j} h_{j}^{t}
$$

where $h_{j}^{t} \equiv H_{j}^{t} /\left(H_{j}^{t}+L_{j}^{t}\right)$ denotes the share of white-collar workers employed in the production of input $j .{ }^{27}$ We exclude inputs purchased within the same sector $(j=i)$. This avoids that skilled workers employed in sector $i$ itself enter its measure of input-embedded skills $\sigma_{i}$, which would bias our results.

A potential concern arises because inputs $X_{i j}$ (and thus input shares $a_{i j}$ ) contain imports from abroad, while the corresponding skill shares $h_{j}$ are measured in U.S. sectors. ${ }^{28}$ However, the resulting measurement error of $\sigma_{i}$ is likely to be minor. The share of imports in non-energy intermediates during the sample period is relatively small, growing from 4\% in 1967 to $13 \%$ in 1992 (see Appendix A.2). Moreover, most U.S. imports of intermediates in this period were sourced from other OECD countries with similar skill intensities. Finally, having a noisy measure of input skill intensity creates attenuation bias against finding skill complementarities across sectors.

By construction, $\sigma_{i} \in[0,1]$ is the weighted average share of white-collar workers involved in the production of sector $i$ 's intermediate manufacturing inputs. A more conservative measure of input skill intensity is obtained by excluding those inputs that are purchased from the same two-digit SIC industry as the good being produced. We implement this idea by restricting the four-digit industry subscripts $i$ and $j$ in (12) to be outside the same two-digit SIC industry. This measure addresses the concern that skill upgrading may happen simultaneously in similar industries, which would imply a spurious correlation of input and final production skill intensities when similar sectors buy each other's inputs. The resulting measure is labeled $\sigma_{i}^{2 \mathrm{~d}}$.

Input skill intensity is distributed between .062 and .56 with mean .25 and standard deviation .55 . Sectors with relatively constant (or declining) $\sigma_{i t}$ between 1967 and 1992 are mainly textile and food industries, such as 'Leather tanning \& finishing,' or 'Yarn mills. ${ }^{29}$ These tend to use primary inputs, which in turn changed little or dropped in terms of white-collar employment shares. Industries that experienced the largest increase in input skill intensity include various electronic, computing, and communication equipment, as well as aircraft and space industries, all of which intensively use high-tech inputs that experienced innovation and skill-upgrading throughout the last decades.

\footnotetext{
${ }^{26}$ This would be a strong assumption if input shares shifted systematically towards more (or less) skill intensive industries, which is not the case, as we show in section 5.2.

${ }^{27}$ Alternatively, $\sigma_{i}^{w}$ can be calculated, using wage-bill instead of employment shares: $h_{j}^{w} \equiv w_{H, j} H_{j} /\left(w_{H, j} H_{j}+w_{L, j} L_{j}\right)$, where $w_{H, j}$ and $w_{L, j}$ denote white- and blue-collar wages, respectively. Regression results do not change when using $\sigma_{i}^{w}$.

${ }^{28}$ Unfortunately, the BEA provides import matrices only from 1997 on. But even these numbers are approximations and do not include the source country. Actual data on domestic vs. imported content of an industry's intermediate inputs are, for the most part, not available.

${ }^{29}$ Sectoral levels of input skill intensity are not important for our empirical results - they are taken up by industry fixed effects in the regressions.
} 
In order to identify the degree of differentiation for each sector's inputs, we use data from Rauch (1999). Rauch groups goods into 1,189 industries according to the 4-digit SITC Rev. 2 system. An industry's product is classified as differentiated if it is neither traded on an organized exchange nor reference priced in trade publications. ${ }^{30}$ We aggregate the Rauch data into the 358 SIC industries of our sample. This procedure yields data on the fraction of each industry's output that is differentiated. ${ }^{31}$ Using this information, along with the input shares derived above, we define the degree of input differentiation:

$$
\kappa_{i}=\sum_{j \neq i} \bar{a}_{i j} R_{j}^{\mathrm{diff}}
$$

where $R_{j}^{\text {diff }}$ is the proportion of input $j$ that is classified as differentiated. The measure $\kappa_{i}$ is therefore the weighted average share of a sector's inputs (purchased outside the same sector) that are differentiated. ${ }^{32}$ It has a minimum of .059 , maximum .96 , mean .52 , and standard deviation .18 .

\section{Data on product innovation}

We use data from Scherer (1982) to derive, for each industry, its share of R\&D spent for product innovation, $\pi_{i}^{\text {prod }}{ }^{33}$ In the empirical analysis $\pi_{i}^{\text {prod }}$ serves to investigate the relationship between product innovation and product differentiation, given by $R_{i}^{\text {diff }}$. In order to perform this analysis, we match our 4-digit SIC code to Scherer's 36 manufacturing industries and aggregate $R_{i}^{\text {diff }}$ to this level of detail, using sectoral shipments as weights. The resulting sample includes $\pi_{i}^{\text {prod }}$ and $R_{i}^{\text {diff }}$ for 34 manufacturing sectors $\left(2\right.$ observations of $\pi_{i}^{\text {prod }}$ are missing). $\pi_{i}^{\text {prod }}$ has mean .66 and standard deviation .27. The share of product innovation is smallest in primary industries like wood products, ferrous metals, or petroleum, and is largest in various machinery and equipment industries, including photo, medical instruments, communication and construction equipment.

\section{Additional control variables}

In the empirical analysis we include several variables that have been previously used to explain increasing wage inequality. In the following we describe these variables briefly. Appendix A.2 provides more de-

\footnotetext{
${ }^{30}$ Rauch provides liberal and conservative estimates. We use the former, but none of the results presented in the following depend on this choice.

${ }^{31}$ Nunn (2007) describes the construction of a crosswalk from the 4-digit SITC to the BEA's 1987 4-digit SIC classification. He kindly shared his data. These aggregate into 302 sectors of our sample. For the remaining 56 sectors we use a correspondence from 4-digit SITC to 4-digit SIC provided by Pamela Lowry (downloadable from Jon Haveman's Industry Trade page). Following Nunn, we apply equal weights when aggregating SITC industries to the SIC classification.

${ }^{32}$ This variable is similar to Nunn's (2007) measure of relationship specificity; but Nunn uses Rauch's classification in a different context, showing that countries with good contract enforcement specialize in the production of goods that require relationshipspecific investments.

${ }^{33}$ For example, in the United States in 1982, $86 \%$ of all R\&D expenditures in the Lumber and Wood sector improved production processes, and only $14 \%$ of innovations left this sector in the form of better products. The opposite holds for Industrial Electrical Equipment, where $85 \%$ of R\&D was devoted to product innovation, benefitting other sectors that use electrical equipment. Appendix A.2 explains the corresponding methodology in detail.
} 
tail. Krusell et al. (2000) argue that the stock of capital equipment is complementary to skilled labor. To control for this capital-skill complementarity, we include real capital equipment per worker, $k^{\text {equip }}$, and in addition real capital structures per worker $k^{\text {struct }}$. Data on research and development (R\&D) intensity are from the National Science Foundation (NSF). Following Autor et al. (1998), we use lagged R\&D intensity $\left(R \& D_{\text {lag }}\right)$ in the regressions. ${ }^{34}$ We use data from the BEA to construct sectoral shares of high-technology capital $(H T / K)$ and office, computing \& accounting equipment $(O C A M / K) .{ }^{35}$ Feenstra and Hanson (1999) document a significant impact of foreign outsourcing on relative wages. We calculate their broad (OS $\left.{ }^{\text {broad }}\right)$ and narrow $\left(O S^{\text {narr }}\right)$ measures of outsourcing for the years and sectors included in our sample. Feenstra and Hanson argue that the narrow measure - from within the same two-digit industry - best captures the idea of outsourcing. For example, the import of steel by a U.S. automobile producer is normally not considered as outsourcing, while it is common to think of imported automobile parts by that company as outsourcing. Following this reasoning, we use $O S^{\text {narr }}$ in most regressions, including $O S^{\text {broad }}$ in the robustness checks.

Table 1 reports the pairwise correlations between two measures of input skill intensity $\left(\sigma_{i}\right.$ and $\left.\sigma_{i}^{2 \mathrm{~d}}\right)$ and the most prominent control variables. As in most of the following analyses, these correlations are obtained after controlling for industry and time fixed effects. The two measures of input skill intensity are highly correlated with one another, and are also correlated with control variables commonly used in the SBTC literature. Industries using skill-intensive intermediates tend to be capital and R\&D intensive, employ hightech capital, and outsource the production of their intermediates.

\section{[Insert Table 1 here]}

\section{Empirical Results}

In this section, we test predictions P1-P3. When analyzing P1 and P2, we focus on correlation coefficients. First we show that the novel stylized fact presented in the introduction is not an artifact: The correlation between input skill intensity and final production skill shares is robust to a variety of additional controls and specifications. Next, we provide evidence suggesting that ITSC works through product innovation, showing that its strength varies systematically with the degree of input differentiation. Finally, we examine ITSC's importance for skill upgrading and address endogeneity issues.

\subsection{Testing P1: Correlation of Skill Intensities across Sectors}

This section investigates the sketch model's first prediction: "The proportion of skilled workers in sectors $i$, $h_{i}$, increases in within-sector skill bias $T_{i}$ and in input skill intensity $\sigma_{i}$." Taking logs in (7) is the first step

\footnotetext{
${ }^{34}$ The first (lagged) period is 1963, implying a 4-year lag. All other lags are 5 years. Because industrial R\&D intensity tends to be persistent over time, working with lagged or contemporaneous R\&D makes almost no difference to the nature of our results.

${ }^{35}$ Both technology measures are widely used in studies of wage inequality. See, in particular, Autor et al. (1998) and Feenstra and Hanson (1999). The capital stock data are likely measured with substantial error, and are often not measured directly but inferred from employment data, assuming relationships between occupations and capital-type usage. See Becker, Haltiwanger, Jarmin, Klimek, and Wilson (2006) for a discussion. This implies an upward bias of computer capital's impact on skill upgrading, stacking the odds against finding an important contribution of input skill intensity.
} 
toward an estimation equation:

$$
\ln \left(\frac{H_{i}}{L_{i}}\right)=\text { const. }+(\epsilon-1) \ln \left(T_{i}\right)+\phi_{i}(\epsilon-1) \ln \left(\sigma_{i}\right)+\epsilon \ln \left(\frac{w_{L}}{w_{H}}\right)
$$

To test P1, we impose $\phi_{i}$ to be constant across sectors $i$. If P1 holds, we expect a positive average coefficient $\phi$. Note that in addition we also need $\epsilon>1$, i.e., $H$ and $L$ are substitutes. ${ }^{36}$ Given this, we estimate the linear equation:

$$
h_{i t}=\alpha_{i}+\alpha_{t}+\beta \sigma_{i t}+\gamma \mathbb{T}_{i t}+\varepsilon_{i t}
$$

where $t$ indexes 5-year periods between 1967 and '92. Following the common identification strategy in the SBTC literature, we use the high-skill labor share $h_{i}$ as dependent variable, which is proportional to $\ln \left(H_{i} / L_{i}\right) .{ }^{37}$ On the right-hand side, $\alpha_{i}$ and $\alpha_{t}$ denote industry and time fixed effects, respectively; $\mathbb{T}_{i t}$ is a set of variables controlling for within-sector skill bias (note that $\gamma$ is a vector of coefficients), $\sigma_{i}$ is input skill intensity as calculated in (12), and $\varepsilon_{i t}$ represents measurement error and unobserved drivers of the skilled labor share. The relative wage in (14) is an aggregate variable and is therefore captured by the time dummies in (15). Controlling additionally for sector-specific relative wages does not change our results, as shown below. ${ }^{38}$

A first look at the data was provided above by Figure 1, plotting a cross-section of $h_{i}$ against $\sigma_{i}$, where both variables were calculated in 1992. The corresponding regression, including a constant term, yields a highly significant coefficient: $\beta=.957$, with a (robust) standard error of .101 . Two concerns arise. First, the observed correlation may be due to unobserved sectoral characteristics that drive both $h_{i t}$ and $\sigma_{i t} .{ }^{39}$ Second, when using a panel, the correlation between $h_{i t}$ and $\sigma_{i t}$ may be spurious, driven by a general trend of skill upgrading. To address these concerns, the first column of Table 2 adds sectoral and time fixed effects to the regression. The coefficient on $\sigma_{i t}$ is highly significant. The number of observations represents the full sample of 6 periods $\times 358$ sectors $=2148$. We report two frequently used measures for the goodness of fit: One including the variation explained by sectoral fixed effects $\left(R^{2}\right)$, and the other assessing the model's fit after accounting for sectoral dummies ( $R^{2}$ within). The former is close to one, while the latter implies that the regressions presented in Table 2 account for roughly half of the variation of $h_{i t}$ within sectors over time.

\section{[Insert Table 2 here]}

Next, we control for capital endowments as determinants of skill upgrading. Krusell et al. (2000) argue

\footnotetext{
${ }^{36}$ In a Cobb-Douglas production function with $\epsilon=1$, technological progress favoring one factor has no impact on relative demand. Empirical studies typically find $\epsilon$ between 1.4 and 2 (Angrist, 1995; Ciccone and Peri, 2005).

${ }^{37}$ The proportionality is very close to linear over the relevant range in the dataset, with percentiles $p_{1}(h)=0.093$ and $p_{99}(h)=$ 0.634. None of the empirical results change when we use $\ln \left(H_{i} / L_{i}\right)$ instead.

${ }^{38}$ The sector-specific skill premium $w_{H, i} / w_{L, i}$ captures mostly cross-industry variation in wages, for example due to differences in worker quality. Because of its endogeneity with skill demand, this variable is usually not included in regressions where the dependent variable is the share of skilled workers. See Feenstra (2004, ch. 4) for a discussion.

${ }^{39}$ One such story would be that the skill share in both final and the corresponding intermediate production is determined by technological history. Suppose that 'old' sectors are low-skill intensive, buying mainly 'old' inputs, while 'modern' sectors employ skilled workers and purchase 'modern' inputs. This would yield the observed correlation even in the absence of intersectoral technology-skill complementarities.
} 
that there is a strong complementarity between capital equipment and skilled labor in the aggregate U.S. economy. As column 2 shows, this finding is not reproduced at the detailed industry level; the coefficient on $k^{\text {equip }}$ has the wrong sign and is significant at the $10 \%$ level. ${ }^{40}$ We also include capital structures, which are skill-neutral in the aggregate setup of Krusell et al. (2000), and on the verge of influencing sector-specific skill upgrading significantly in our sample. The share of high-tech capital correlates significantly positively with the proportion of skilled labor, resembling the well-documented complementarity. This variable has more explanatory power than the alternative measure that only includes office, computing, and accounting equipment. Finally, and most important for our results, the coefficient of input skill intensity is robust to the inclusion of capital controls. The same holds when further controls are included, as shown in column 3. The sample size is now 2089 due to missing observations in the outsourcing measure. Both lagged R\&D intensity and outsourcing have a significantly positive correlation with skilled labor in final production, which confirms previous findings (Machin and van Reenen, 1998; Feenstra and Hanson, 1999). Column 4 shows the results without time dummies. As expected, because of the general skill upgrading over time, the coefficient of input skill intensity is now slightly larger.

The last two columns of Table 2 present regression results for alternative measures of input skill intensity, including all controls. In column $4, \sigma_{i}^{2 \mathrm{~d}}$ is used, excluding inputs purchased within the same 2-digit industries. This specification addresses the concern that common trends or technology shocks may drive skill upgrading in similar industries, biasing $\beta$ upwards when these industries are linked via input-output relationships. The more conservative measure comes along with a cost: $\sigma_{i}^{2 \mathrm{~d}}$ discards a substantial part of intersectoral linkages, since sectors purchase on average $35 \%$ of their inputs within the same 2-digit category. ${ }^{41}$ Therefore, $\sigma_{i}^{2 \mathrm{~d}}$ is a more noisy measure of input skill intensity and likely subject to attenuation bias. Nevertheless, the coefficient $\beta$ is only slightly smaller than in the previous specifications and still highly significant. We implement two additional ways to address the common-shock concern. Both are based on specification 3 and are not reported in the table. First, we use the 5-year lag of $\sigma_{i}$. The coefficient on $\sigma_{i, t-5}$ is highly significant, .366 (.095), with all other coefficients very similar to those reported in columns 3 and 5 . This finding mitigates the common-shock concern - to maintain it, one would have to argue that downstream skill demand reacts half a decade later than its upstream counterpart to the same shock. Second, we include time dummies at the 2-digit industry level. These absorb common industry shocks to skill demand, such that the coefficient $\beta$ only reflects the variation of detailed 4-digit sectors relative to the corresponding 2-digit industries. Even with this restriction, the coefficient remains highly significant and of similar magnitude, $\beta=.401$ (.185).

Column 6 uses $\sigma_{i}^{w}$, where skills in input production are measured with the wage-bill, instead of the labor share of skilled workers (see footnote 27). Berman et al. (1994) propose the wage-bill share as an alternative measure of skill demand, because it also captures skill upgrading within either category - white-collar or

\footnotetext{
${ }^{40}$ This supports the critical view of Krusell et al.'s results, which disappears when a linear time trend is included in the regressions (Acemoglu, 2002b). In fact, if we only include $k^{\text {equip }}$ and sectoral dummies as explanatory variables in (15), the coefficient on $k^{\text {equip }}$ is positive and highly significant. As soon as other controls or time dummies are included, the coefficient becomes insignificant.

${ }^{41}$ One sector, 'Special product sawmills' (SIC 2429) purchases all inputs within the same 2-digit category. The corresponding $\sigma_{i}^{2 \mathrm{~d}}$ is therefore missing in all 6 benchmark years, which leaves 2083 observations.
} 
blue-collar workers. The results obtained with $\sigma_{i}^{w}$ are very similar to the ones with $\sigma_{i}$.

\subsection{Robustness of the Correlation}

The robustness of our results to alternative measures of input skill intensity, $\sigma_{i}, \sigma_{i}^{2 \mathrm{~d}}$, and $\sigma_{i}^{w}$ has been verified in Table 2. These measures were all calculated based on constant input shares, i.e., stable linkages over time. In the following, we first show that our results are robust to including input skill intensity measures based on changing input shares. Second, we test the sensitivity and robustness of our estimates to alternative specifications.

\section{Input skill intensity with changing input shares}

Because input shares $a_{i j}$ vary substantially over time, mostly due to one-time outliers, our baseline input skill intensity measures are derived based on average input shares $\bar{a}_{i j}$. Now, we use the time-varying $a_{i j}$ to construct an alternative input skill intensity measure, $S_{i}^{t}=\sum_{j \neq i} a_{i j}^{t} h_{j}^{t}$. This variable can be decomposed into three parts. First, a skill component $\sigma_{i}^{t}$, as defined in (12), representing constant input expenditure shares with changing skilled labor shares of suppliers. Second, an input-mix component $\tau_{i}^{t}=\sum_{j \neq i} a_{i j}^{t} \bar{h}_{j}$, reflecting varying input shares with constant skilled labor shares of suppliers. This variable grows over time if sector $i$ switches its input mix towards more skill intensive intermediates. Finally, a covariance component $\tau_{i}^{t}=\sum_{j \neq i}\left(a_{i j}^{t}-\bar{a}_{i j}\right)\left(h_{j}^{t}-\bar{h}_{j}\right)-\sum_{j \neq i} \bar{a}_{i j} \bar{h}_{j}$, which grows if sector $i$ switches its input mix towards sectors whose skill intensity rises over time. ${ }^{42}$ Note that $S_{i}^{t}=\sigma_{i}^{t}+\tau_{i}^{t}+\rho_{i}^{t}$. The skill component $\sigma_{i}$ is by far the most important contributor to increases in $S_{i}^{t}$ between 1967 and 1992. The weighted average of $S_{i}^{t}$ increases from 21.2 to 27.6 percent. Of this $6.4 \%$ rise, $6.2 \%$ are due to $\sigma_{i}, 1.3 \%$ to $\tau_{i}$, and $-1.1 \%$ to $\rho_{i}$. As Table 3 shows, the coefficient of $\sigma_{i}$ does not change when the two additional variables are used - it is still above 0.5.

\section{[Insert Table 3 here]}

Once the usual controls are included, neither $\tau_{i}$ nor $\rho_{i}$ are significant, as shown in the second and third column of Table 3. This result was to be expected, given the noise in the input shares used to calculate these variables. ${ }^{43}$ Similarly, we expect attenuation bias and therefore a smaller coefficient when using the composite skill intensity $S_{i}$. Columns 4 and 5 show this result with and without time dummies. The coefficients on $S_{i}$ are, however, still highly significant.

\footnotetext{
${ }^{42}$ The term $\sum_{j \neq i} \bar{a}_{i j} \bar{h}_{j}$ is a constant for each sector $i$ and does not influence estimation results in the presence of sectoral fixed effects.

${ }^{43}$ Less than $1 / 3$ of all relevant (i.e., non-zero) input shares have a time-trend that is significant at the $10 \%$ level. In an additional check not presented here, we calculate $\tau_{i}$ and $\rho_{i}$ using changing input shares whenever the time-trend is significant, and average shares otherwise. Under this method, $\tau_{i}$ is significant at the $5 \%$ level when all controls are included, while the coefficient of $\sigma_{i}$ remains unchanged.
} 
Alternative specifications comprise running the regression in changes, including further controls, and restricting the sample to single years, analyzing cross-sections rather than a panel. Table 4 presents the results. Therein, we include the computer capital share $O C A M / K$ and the difference between high-tech and computer capital share $(H T / K-O C A M / K)$, which represents the fraction of capital services derived from various high-technology assets other than office, computing and accounting machinery. Feenstra and Hanson (1999) suggest this specification, and a similar one for outsourcing: the difference between the broad and narrow measures $O S^{\text {broad }}-O S^{\text {narr }}$, representing the intermediate inputs from outside the two-digit purchasing industry that are sourced from abroad.

\section{[Insert Table 4 here]}

The first column of Table 4 runs the baseline regression in changes, instead of including fixed effects. All variables are in 5-year differences. ${ }^{44}$ The corresponding coefficient on input skill intensity is very similar to the one obtained above, and is again highly significant. In column 2, we turn back to estimating levels, including fixed effects and all previously used controls. Additionally, we control for various other variables that potentially drive skill demand. First, broad outsourcing (as difference to narrow). Second, two measures of the 'complexity' of production processes: the variety of inputs used in production, measured as one minus the Herfindahl index of input concentration for each industry $\left(1-H_{i t}\right)$. This variable is used as a measure of a good's 'complexity' by Blanchard and Kremer (1997) to explain the decline of output when bargaining breaks down along the production chain. The other measure for production 'complexity' is an indicator function for the number of inputs, proposed by Nunn (2007). $I_{i t}^{n_{i t}>\bar{n}_{t}}$ equals one if the number of inputs $n_{i t}$ used in industry $i$ in year $t$ is greater than the median number of inputs used in all industries, $\bar{n}_{t}$. We derive both measures from the year-specific I-O tables. Since more 'complex' production processes require more coordination, we expect these variables to have a positive impact on demand for skilled labor. Third, we include the sector-specific skill premium, or relative wage, to capture differences in cost and quality of skilled workers across sectors. Fourth, we control for productivity by including the real value of shipments, $\ln (Y){ }^{45}$ This variable addresses the concern that productivity increases may be the driver of skill upgrading in both upstream and downstream production. Finally, the share of value added in total cost (derived from the BEA I-O data) controls for the overall importance of labor and capital (as opposed to intermediate inputs) in production. Service-oriented sectors generally have a larger value added share, and also a higher proportion of white-collar labor.

The inclusion of further control variables shown in column 2 of Table 4 changes neither the size nor the high statistical significance of the coefficient on input skill intensity. The last three additional controls are significant and have the expected sign. On the other hand, neither previously suggested measure for

\footnotetext{
${ }^{44} \mathrm{R} \& \mathrm{D}$ intensity is also calculated in actual differences, rather than differences of the lagged variable.

${ }^{45}$ Feenstra and Hanson (1999) use this control variable. Results are very similar when using the natural logarithm of value added, as in Bresnahan et al. (2002).
} 
production 'complexity' has a significant impact on skill demand. ${ }^{46}$ The additional outsourcing measure has the expected positive sign and is significant at the $10 \%$ level. Column 3 presents the regression with the non-production wage-bill share as dependent variable. This measure is frequently used as an alternative to the purely labor based measure, as it also captures skill upgrading within either occupational category (Berman et al., 1994). The wage-bill regression confirms magnitude and significance of the ITSC effect.

In all panel regressions presented so far, we address the concern of inconsistent standard errors due to serially correlated observations by accounting for correlation within sectors across time (i.e., by clustering standard errors). Bertrand, Duflo, and Mullainathan (2004) argue that this correction alone may not fully solve the problem and suggest collapsing the time series information into single periods as a further correction. ${ }^{47}$ The last two columns of Table 4 implement this additional consistency check, presenting crosssectional regressions for the first and the last benchmark year of the sample, 1967 and 1992. Fixed effects cannot be used in this specification, raising the concern that unobserved characteristics, like similarity of sectors, drive the correlation between input skill intensity and the skilled labor share in final production. To address this concern, we use $\sigma_{i}^{2 \mathrm{~d}}$ as the input skill intensity measure, excluding linkages within 2-digit industries. The corresponding coefficient is of the same magnitude as observed before, significant in 1967, and highly significant in 1992. Most control variables also confirm the previous findings. Capital equipment turns out negatively significant in the 1992 cross section. ${ }^{48}$ In the panel, $k^{\text {equip }}$ shows up negative and significant in some specifications. These findings together argue against an equipment-skill complementarity. The more narrow high-tech capital variable, however, shows up significantly positive in the cross-section, as well. Finally, production 'complexity', measured by $I_{i}^{n_{i}>\bar{n}}$, correlates positively and significantly with skill demand in the 1992 cross-section.

\subsection{Testing P2: Input Differentiation and Channel of ITSC}

In this section, we examine prediction $\mathrm{P} 2$, which states that the correlation between $h_{i}$ and $\sigma_{i}$ can vary by sector, and is the stronger the larger the extent to which skill bias in upstream technology influences downstream skill bias. Testing P2 hinges on the channel through which intersectoral technology-skill complementarity works. In the framework analyzed here, upstream and downstream sectors are linked through intermediate products. Intermediates are thus a natural starting point to look for the ITSC channel. But how can intermediates transmit skill bias across sectors? They can do so if skilled workers (or their ideas) shape intermediate products in such a way that skills are needed in their further processing. The channel is then product innovation. The following example illustrates this point. Suppose that Exxon decides to boost productivity in oil extraction and hires a large number of engineers. More skills will shape the extraction process, but not the product - crude oil. Consequently, skill demand in a downstream refinery will be unaf-

\footnotetext{
${ }^{46}$ The two complexity measures vary little over time, and the inclusion of sector fixed effects eliminates much of their variation. In fact, when running the same regression without sector dummies, the coefficient of $I_{i}^{n_{i}>\bar{n}}$ is positive and significant, but does not affect input skill intensity.

${ }^{47}$ Long time series (15 periods and more) are a major contributing factor to Bertrand et al.'s concern. Since our panel involves only 6 periods, the concern is likely of minor importance, given that we are already controlling for serial correlation.

${ }^{48}$ This finding is robust and also appears when only capital structures and equipment are included in the regression.
} 
fected by Exxon's move. On the other hand, trained engineers inventing ever better and smaller data storage devices enabled Apple to launch the iPod - a highly skill-intensive endeavor. ${ }^{49}$ Crude oil is a homogenous product, while data storage devices are differentiated. Our testing of $\mathrm{P} 2$ is built around this classification.

Analytically, we follow a two-step process. First, we show that sectors producing differentiated products spend relatively more R\&D for product innovation, while producers of homogenous goods concentrate on innovating their own processes. This suggests that differentiated products embody more innovation than homogenous ones. Therefore, sectors using differentiated intermediates purchase relatively more embodied product innovation, which leads to the second step: If ITSC works through product innovation, we expect it to be stronger for sectors that use relatively more differentiated inputs. We provide evidence that is in line with this assertion.

\section{Product innovation and product differentiation}

As described in section 4, we derive sectoral shares of R\&D expenditures used for product innovation, $\pi_{i}^{\text {prod }}$, from Scherer's (1982) data, and match them to Rauch's (1999) data on product differentiation. This gives $\pi_{i}^{\text {prod }}$ together with the share of products classified as differentiated, $R_{i}^{\text {diff }}$, for 34 manufacturing industries. The median of $R_{i}^{\text {diff }}$ in this sample is .84 . The 17 industries turning out goods with below-median product differentiation spend on average $53 \%$ of R\&D for inventing new products (as opposed to processes), while this number is $80 \%$ for producers of above-median differentiated goods. After this preliminary observation, we turn to the simple regression $\pi_{i}^{\text {prod }}=\delta_{0}+\delta_{1} R_{i}^{\text {diff }}+\varepsilon_{i}$, where the last variable represents an error term. The corresponding estimate is positive and highly significant: $\delta_{1}=.416$ with a robust standard error of .127 and $R^{2}$ of $0.27 .^{50}$ These findings suggest that differentiated products are more susceptive to product innovation, such that they are more readily reshaped by the innovative minds of skilled workers.

\section{Input differentiation and ITSC}

Skill-biased innovation in one sector passes via intermediate linkages to other sectors, where it can foster further innovation and skill demand. As we have seen, purchasers of differentiated inputs buy on average more innovation incorporated in their intermediates than users of homogenous inputs. Therefore, input differentiation gives the degree to which skill-biased innovation can be 'embedded' in intermediates. We consequently expect stronger ITSC when input-output linkages involve more differentiated intermediates. The corresponding measure $\kappa_{i}$, as described in section 4 , gives the weighted average degree of input differentiation. If $\mathrm{P} 2$ holds, we expect a larger $\beta$ in (15) for sectors with larger $\kappa_{i}$.

To obtain a first look at the data, we use $\kappa_{i}$ to split the sample into sectors with below- and abovemedian input differentiation. Then we estimate regression (15) for the two subsamples and report the results

\footnotetext{
${ }^{49}$ The story also works in the opposite direction. When Apple works on improvements for the next-generation iPod, it creates demand for more powerful memory devices. Both causal directions are compatible with the ITSC framework.

${ }^{50}$ The result is practically identical when using Rauch's (1999) conservative estimate to construct $R_{i}^{\text {diff }}$. Outliers are not an issue, and even excluding the 9 sectors that produce only differentiated products $\left(R_{i}^{\text {diff }}=1\right)$ leaves the remaining ones with a significantly positive $\delta_{1}$.
} 
in Figure 2 in the form of partial scatter plots. The vertical axis shows the variation in the skilled labor share $h_{i}$ to be explained by input skill intensity $\sigma_{i}$, after controlling for fixed effects and statistically significant control variables (all controls that were significant in at least one specification in Table 2).

\section{[Insert Figure 2 here]}

The left panel of Figure 2 shows the partial scatterplot for the full sample, where the corresponding coefficient from regression (15) is $\hat{\beta}=.590 .51$ The right panel repeats the exercise for two subsamples, one with sectors purchasing relatively homogenous inputs (below-median $\kappa_{i}$ ) and the other comprising sectors that use more differentiated inputs (above-median $\kappa_{i}$ ). These first results show that ITSC is stronger for sectors using more differentiated inputs than for those using more homogenous ones; the corresponding coefficients are $\hat{\beta}^{\text {diff }}=.848$ and $\hat{\beta}^{\text {hom }}=.479$, respectively. ${ }^{52}$ In addition, the two subsamples have different final production skill shares. Sectors using more differentiated inputs are on average more skill intensive $\left(\bar{h}^{\text {diff }}=.286\right.$ vs. $\left.\bar{h}^{\text {hom }}=.245\right)$. This is what we expect, given that differentiated inputs incorporate more product innovation.

Next, we include interaction terms of explanatory variables with input differentiation $\kappa_{i}$. This yields the following extended estimation equation: ${ }^{53}$

$$
h_{i t}=\alpha_{i}+\alpha_{t}+\beta_{1} \sigma_{i t}+\beta_{2} \kappa_{i} \times \sigma_{i t}+\gamma_{1} \mathbb{T}_{i t}+\gamma_{2} \kappa_{i} \times \mathbb{T}_{i t}+\varepsilon_{i t}
$$

Table 5 reports the results, using the three alternative measures for input skill intensity, $\sigma_{i}$ (baseline), $\sigma_{i}^{2 \mathrm{~d}}$ (excluding inputs from the same 2-digit sectors), and $\sigma_{i}^{w}$ (calculated based on the high-skill wage bill share). The interactions 'input differentiation' $x$ 'input skill intensity' are positive and highly significant, implying that ITSC grows with the degree of input differentiation. Moreover, the coefficient on input skill intensity $\left(\beta_{1}\right)$ becomes small and insignificant when the usual controls are included. This indicates that ITSC is not present for a (hypothetical) sector using only homogenous inputs $\left(\kappa_{i}=0\right)$. To see this, note that the marginal effect of input skill intensity on final production skills is given by $\partial h_{i} / \partial \sigma_{i}=\beta_{1}+\beta_{2} \kappa_{i}$. On average, the estimated ITSC is slightly larger than above, where input differentiation was not controlled for. In addition to supporting P2, the interaction results also argue against the concern that the documented ITSC is a spurious correlation. ITSC is not present where we do not expect it to appear, and it becomes stronger where we expect intersectoral skill complementarities to play a more important role.

\section{[Insert Table 5 here]}

\footnotetext{
${ }^{51}$ To ease graphical exposition, the regressions in Figure 2 use equal weights for each sector. The estimated coefficient is very similar when weighted by employment shares, $\hat{\beta}=.558$. The plot also shows that the positive correlation between input skill intensity and final production skills is a broad phenomenon, not driven by outliers.

${ }^{52} \mathrm{~A}$ more detailed analysis, using quintiles of input differentiation $\kappa_{i}$, confirms this result: $\hat{\beta}$ increases with each quintile of $\kappa_{i}$ and is highly significant for all except the first one.

${ }^{53}$ Because the framework analyzed here involves complementarity among several explanatory variables, we also interact the control variables with input differentiation. This addresses the concern that the $\sigma_{i} \times \kappa_{i}$ interaction alone might capture other effects related to product differentiation. This is the case, for example, if the processing of differentiated intermediates is more R\&D intensive, or if outsourcing is more pronounced for differentiated inputs, influencing skill demand through these channels. Input differentiation $\kappa_{i}$ is not included in the regressions, as it is captured by sectoral fixed effects.
} 


\subsection{Prediction 3: Importance of ITSC}

So far, we have seen that the correlation between input skill intensity and the downstream share of skilled labor is highly significant and robust to the inclusion of various controls. We have interpreted this finding as evidence for technology-skill complementarity across sectors. Next, we turn to the importance of ITSC for increasing skill demand. According to prediction 3, ITSC reinforces skill demand along the production chain, which leads to the multiplier effect given in (10). Its magnitude follows from the average strength of ITSC, $\phi$. In an ideal world, we would know the exact functional form of (7) and especially (9) to pin down $\phi$ from the data. In the real world, however, models are often misspecified, and so is - almost certainly the stylized one in this paper. Misspecification can cause inconsistent parameter estimates. To alleviate this concern, we use an estimation framework that imposes few restrictions on the model structure. A translog cost functions allows for this flexibility.

We apply a framework that has been used to estimate the impact of trade and technological change on the demand for skilled labor. The underlying idea is that structural variables like R\&D intensity, computer capital, or input skill intensity can shift the production function and therefore the optimal choice of skilled vs. unskilled labor. Because some structural variables are arguably endogenous, we use instruments in the corresponding estimation. Our results suggest that ITSC contributes importantly to skill upgrading in U.S. manufacturing - with a similar impact as computers and high-tech capital.

\section{A labor demand framework}

In the following we derive a labor demand regression from a model with sector-specific technologies that are influenced by structural variables. ${ }^{54}$ Feenstra and Hanson (1999) argue that labor demand shifting structural variables comprise fixed capital, computing equipment, and outsourcing. We add R\&D intensity and input skill intensity to this list. The former has been identified as an important determinant of skill demand (e.g., Machin and van Reenen, 1998), while the inclusion of the latter is motivated by the empirical evidence presented above.

The production function in sector $i$ takes the form $Y_{i}=F_{i}\left(H_{i}, L_{i} ; \sigma_{i}, \mathbb{T}_{i}\right)$, where structural variables, $\sigma_{i}$ and $\mathbb{T}_{i}$, are fixed in the short run, while skilled and unskilled labor, $H_{i}$ and $L_{i}$, are chosen optimally. Consequently, a firm in sector $i$ minimizes its wage bill $w_{H} H_{i}+w_{L} L_{i}$ subject to the corresponding production technology, taking as given high-skill and low-skill wages, $w_{H}$ and $w_{L}$, as well as input skill intensity $\sigma_{i}$ and other structural variables $\mathbb{T}_{i}$. This yields the short-run cost function: $C_{i}\left(w_{H}, w_{L} ; \sigma_{i}, \mathbb{T}_{i}, Y_{i}\right)$. Next, we need to choose a functional form. The translog cost function is a convenient choice, as it imposes no a-priori restrictions on elasticities of substitution and returns to scale. ${ }^{55}$ We then use Shephard's Lemma, which states that the derivative of the cost function with respect to $w_{H}$ gives the demand for skilled labor, $H_{i}$. This final step is the centerpiece of the demand framework - it enables us to analyze factor demand by

\footnotetext{
${ }^{54}$ For a more detailed exposition see Katz and Murphy (1992) and Feenstra (2004, ch. 4).

${ }^{55}$ See Kim (1992) for a general discussion of the translog function. In order to derive the estimation equation below, we assume that the translog cost function is homogenous of degree one in wages.
} 
examining the properties of the first derivative of the cost function. As shown in Feenstra (2004, ch. 4), we obtain the estimation equation

$$
\triangle h_{i t}^{w}=\alpha+\beta \triangle \ln \sigma_{i t}+\gamma \triangle \ln \mathbb{T}_{i t}+\delta \triangle \ln Y_{i t}+\eta \triangle \ln \left(\frac{w_{H, t}}{w_{L, t}}\right)+\varepsilon_{i t}
$$

where $h_{i}^{w}=\left(w_{H} H_{i}\right) /\left(w_{H} H_{i}+w_{L} L_{i}\right)$ is the wage bill share of skilled (white-collar) workers. This equation says that the relative demand for skilled labor, represented by its cost share, depends on the structural variables $\sigma_{i}$ and $\mathbb{T}_{i}$, and on the relative wage. Intuitively, for a given relative wage, structural variables shift the relative demand for the two types of labor, as captured by the coefficient $\beta$ and the vector of coefficients $\gamma$.

\section{Contributions without input skill intensity}

The first specification in Table 6 presents an estimation of (17), following the strategy outlined in Feenstra and Hanson (1999). Input-skill intensity is not yet included in the regression. The structural variables $\mathbb{T}_{i t}$ comprise the previously used drivers of skill demand (see Table 2). In addition, (17) implies that we also have to control for the real value of shipments, $\ln Y_{i t}$, and the relative wage $\left(w_{H, t}\right) /\left(w_{L, t}\right)$. In the data, the latter varies across $i$ because of cross-industry variation in wages, for example due to quality variation of workers. ${ }^{56}$ Multiplying the regression coefficients by the 1967-92 change in the corresponding variable (shown in the first column) gives each structural variable's contribution to the increase in the white-collar wage bill share. If we divide this number by the total change in the white-collar wage bill share 1967-92 (0.0727), we obtain percentage contributions. In the first specification, high-tech capital contributes about $12 \%$ to overall skill upgrading, and outsourcing (broad and narrow) delivers another 17\%. Both numbers are in the ranges documented by Feenstra and Hanson (1999) for the period 1979-90. ${ }^{57}$ While the coefficient of $R \& D$ intensity is large, its contribution to rising skill demand is not. This is because $R \& D$ intensity itself increased relatively little. Broad capital is roughly skill neutral, with the positive contribution of structures offsetting the negative impact of equipment. Overall, the results in the first column of Table 6 replicate previous findings and confirm the empirical gap in explaining skill demand increases. ${ }^{58}$

\section{[Insert Table 6 here]}

\section{Instrumenting for input skill intensity}

In the intersectoral complementarity framework presented above, endogeneity and reverse causality are potential concerns. Causality could run in either direction - from upstream to downstream skill intensity ( $\sigma_{i}$ to

\footnotetext{
${ }^{56}$ Results are very similar when relative wages are dropped from the regressions. See footnote 38 for a more detailed discussion.

${ }^{57}$ The contribution of high-tech capital is at the lower end of Feenstra and Hanson's findings, which is likely due to the longer time horizon in our sample, starting in 1967. In other specifications (see columns 2 and 3), however, the number is closer to the usually reported roughly one third.

${ }^{58}$ Even with a larger contribution of high-tech capital - say the commonly reported $30 \%$ - the overall explained increase would barely exceed one half. This coincides with the total skill demand increase explained by previous studies that we reviewed in section 1.
} 
$h_{i}$ ), or the other way around. ${ }^{59}$ In the following we treat $\sigma_{i}$ as a structural variable that can shift the demand for skilled labor in downstream sectors. We must therefore find instruments that explain skill upgrading at the upstream level but do not have an impact on downstream skill demand other than through intermediate linkages. To derive candidates for such instruments, we restate ITSC in a simultaneous equations model:

$$
\begin{array}{r}
h_{i t}=\alpha_{1, i}+\beta_{1} \sigma_{i t}+\gamma_{1} \mathbb{T}_{i t}+\varepsilon_{1, i t} \\
\sigma_{i t}=\alpha_{2, i}+\beta_{2} h_{i t}+\gamma_{2} \mathbb{T}_{j \neq i, t}+\varepsilon_{2, i t}
\end{array}
$$

The first equation represents the upstream-downstream direction of ITSC, estimating the impact of input skill intensity on final production skill demand. $\mathbb{T}_{i t}$ is the usual set of within-sector control variables. The second equation describes the opposite causal direction - the impact of downstream skill share $h_{i}$ on skill intensity in upstream sectors $j \neq i$ (i.e., $\sigma_{i}$ ). ${ }^{60}$ Slightly abusing notation, denote elements of $\mathbb{T}$ by $T$. Individual within-sector control variables that affect the skill demand in intermediate production, $T_{j \neq i, t}$, are constructed in a similar fashion as $\sigma_{i t}$ :

$$
T_{j \neq i, t}=\sum_{j \neq i} \bar{a}_{i j} T_{j t}
$$

For example, let $T_{j t}$ be R\&D intensity of intermediate supplier $j$. We expect this variable to affect $\sigma_{i t}=$ $\sum_{j \neq i} \bar{a}_{i j} h_{j t}$ through its impact on $h_{j t}$. This holds for all suppliers $j \neq i$. In this example $T_{j \neq i, t}$ thus represents weighted average R\&D intensity of sector $i$ 's suppliers. The same methodology applies to computer and high-tech capital as well as outsourcing. All are summarized as $\mathbb{T}_{j \neq i, t}{ }^{61}$

Deriving the reduced form for $\sigma_{i t}$ from (18) and (19) gives the first stage of an instrumental variable (IV) regression, with $\mathbb{T}_{j \neq i, t}$ as instruments for $\sigma_{i t}$ :

$$
\sigma_{i t}=\tilde{\alpha}+\tilde{\gamma}_{1} \mathbb{T}_{i t}+\tilde{\gamma}_{2} \mathbb{T}_{j \neq i, t}+\tilde{\varepsilon}_{i t}
$$

Writing this in changes, we could use $\triangle \mathbb{T}_{j \neq i, t}$ to instrument for $\triangle \sigma_{i t}$ in (17). Being conservative, we use the 5-year lags, $\triangle \mathbb{T}_{j \neq i, t-5}$, as instruments. ${ }^{62}$ This alleviates remaining endogeneity concerns - especially the one that common trends in I-O linked industries drive our results.

Intuitively, the IV strategy says that rising R\&D expenditures, computer use, and outsourcing in an up-

\footnotetext{
${ }^{59}$ As a first pass at the issue, we use a Granger causality test. The usual cavaets apply - time precedence and causality are two distinct concepts. We find Granger causality in both directions: stronger in the upstream-downstream direction, where the coefficient on lagged $\sigma_{i}$ is .179 (.054); and weaker in the opposite direction with a coefficient on lagged $h_{i}$ of .033 (.015). All lags are 5 years; both regressions include all lagged control variables used in Table 2, sectoral dummies, and the lag of the left-hand side variable.

${ }^{60}$ These two equations can be used to quantify the bias that arises when we interpret the OLS coefficient $\beta$ from equation (15) as a causal impact of $\sigma_{i t}$ on $h_{i t}$, not taking into account the reverse relationship. The covariance between $\sigma_{i t}$ and $\varepsilon_{1, i t}$ is given by $\beta_{2} /\left(1-\beta_{1} \beta_{2}\right) \operatorname{Var}\left(\varepsilon_{1, i t}\right)$, and the corresponding bias in $\beta$ is equal to this covariance divided by $\operatorname{Var}\left(\sigma_{i t}\right)$. The Granger causality test suggests that the feedback from $h_{i t}$ to $\sigma_{i t}$ is small in comparison to the opposite direction. We thus expect that $\beta_{2}$ is small, which yields a small positive bias of the OLS coefficient in (15).

${ }^{61}$ The set $\mathbb{T}_{j \neq i}$ that we use in the IV regressions comprises $(H T / K)_{j \neq i},(O C A M / K)_{j \neq i}, O S_{j \neq i}^{\text {narr }}, O S_{j \neq i}^{\text {broad }}-O S_{j \neq i}^{\text {narr }}$, and $(R \& D)_{j \neq i}$.

${ }^{62}$ Recall that the manufacturing industry panel has 5 -year intervals. Using the contemporaneous $\triangle \mathbb{T}_{j \neq i, t}$ gives similar results but is more amenable to endogeneity concerns.
} 
stream sector drive skill upgrading there. The exclusion restriction is that instruments $\triangle \mathbb{T}_{j \neq i, t-5}$ influence upstream skill intensity $\triangle \sigma_{i t}$ but are uncorrelated with the downstream skill share $\triangle h_{i t}^{w}$ after controlling for $\triangle \mathbb{T}_{i t}$ in the second stage, i.e., in (17). For the IV strategy to work, we have to assure that (i) lagged changes in high-tech capital, outsourcing, or R\&D at the upstream level influence upstream skill demand and (ii) do only have an impact on downstream skill demand through the intermediate linkage channel. The first part is well-founded, as our own and other previous findings in the literature show. ${ }^{63}$ Although less evident, it is reasonable to argue that the instruments also fulfill the second requirement. Recall that the set $\mathbb{T}$ denotes within-sector drivers of SBTC that should have no direct impact on skill demand in other sectors. For example, it is hard to maintain that more computers or $\mathrm{R} \& \mathrm{D}$ in intermediate production lead to higher skill demand in final production for reasons different from an innovation-skill channel. This is especially true because cross-sector compatibility motives for computer adoption would be captured by computers showing up as a control variable in the second stage regression (17). This makes a direct impact of the instruments $\triangle \mathbb{T}_{j \neq i, t-5}$ on $\triangle h_{i t}^{w}$ unlikely. But what about common trends? More specifically, the concern is that trends in high-tech capital adoption, outsourcing, or $\mathrm{R} \& \mathrm{D}$ can be correlated across upstream and downstream industries, in particular if the production chain involves similar industries. This could lead to

$\triangle \mathbb{T}_{j \neq i, t-5}$ influencing $\triangle h_{i t}^{w}$ because both correlate with $\triangle \mathbb{T}_{i t}$. Including the downstream variables $\triangle \mathbb{T}_{i t}$ in the second stage regression (17) controls for this channel.

Summing up, we are able to alleviate the most serious concerns regarding $\triangle \mathbb{T}_{j \neq i, t-5}$ as instruments for $\triangle \sigma_{i t}$. However, it is important to mention that the instruments are not completely satisfactory. Endogeneity remains a concern if three things come together: unobserved shocks or innovations hit similar industries simultaneously, these industries are linked through intermediates, and the shocks influence changes in skill demand and the $\mathbb{T}$-variables over a long horizon (>5 years). Empirically, we have the means to shed light on this concern using overidentification restrictions. The results are encouraging (see below).

\section{Instrumenting for control variables}

Having addressed the endogeneity of $\sigma_{i t}$, we turn to the same concern for other structural variables in the demand framework - the within-sector drivers of SBTC, $\mathbb{T}_{i t}$. To tackle the potential bias, we use an approach outlined in Wooldridge (2002, ch. 11). Under sequential exogeneity, we can use lagged levels of $\mathbb{T}_{i t}$ as instruments for $\triangle \mathbb{T}_{i t}$, which gives consistent estimates and is similar in spirit to Arellano and Bond (1991). Sequential exogeneity implies that if we run regression (17) in levels, then after the structural variables $\left(\mathbb{T}_{i t}\right.$ and $\left.\sigma_{i t}\right)$ and sectoral fixed effects have been controlled for, no past values of $\mathbb{T}_{i t}$ or $\sigma_{i t}$ affect the expected value of $h_{i t}^{w}$. To see whether this holds, we include the 5- and 10-year lags of all structural variables in (17), estimated in levels. None is significant at the $10 \%$ level, with the exception of the 10-year lag of $R \& D$. This suggests that sequential exogeneity is a reasonable assumption for the structural variables in our demand framework. As suggested in Wooldridge (2002, ch. 11), we thus use the 5- and 10-year lags of control variables as instruments for the contemporaneous 5-year changes. The same methodology also

\footnotetext{
${ }^{63}$ Note that variations in high-tech capital or R\&D across sectors may also capture variations in (unobserved) innovative activity. This poses no problem to $\triangle \mathbb{T}_{j \neq i, t-5}$ as instruments - to the contrary: it is in line with the innovation-skill channel of ITSC.
} 
delivers the 5- and 10-year lags of $\sigma_{i t}$ as additional instruments for $\triangle \sigma_{i t}{ }^{64}$

\section{Results with input skill intensity}

Following this discussion, we turn to the IV estimation results. The second specification in Table 6 adds instrumented input skill intensity to the regression. As the number of observations in column 2 reflects, the choice of lagged changes as instruments comes at the cost of an additional time period (with one period already lost due to first differencing). The IV coefficient of input skill intensity is highly significant and smaller than in the OLS specification. ${ }^{65}$ This makes sense, given that we expect an upward bias of OLS estimates (see footnote 60). Input skill intensity contributes roughly one third to the overall increase of the white collar wage bill share in U.S. manufacturing. This is large - about as much as previous estimates assign to computers, and double the contribution of outsourcing or R\&D. Interestingly, input skill intensity is orthogonal to other proposed drivers of SBTC. The latter remain largely unchanged when adding $\triangle \sigma_{i t}$ to the regression.

The instruments for $\triangle \sigma_{i t}$ are highly significant - the corresponding $F$-statistic of the exclusion hypothesis is well above the rule of thumb threshold of 10 recommended by Staiger and Stock (1997) to avoid weak instrument concerns. The additional test of weak instruments based on Stock and Yogo (2002) confirms this result. This test becomes especially useful in models with more than one endogenous variables and is discussed in more detail below. Since the number of instruments is larger than one, we can test for their endogeneity using the Sargan-Hansen test of overidentifying restrictions. The corresponding $p$-value is .78. We therefore do not reject instrument exogeneity.

Finally, we turn to specification 3, where we additionally instrument for within-sector drivers of skill upgrading. The Staiger and Stock (1997) rule of thumb for avoiding weak instruments refers to models with one endogenous variable. In models with two or more endogenous variables, instruments can be weak despite being significant in each first-stage regression. This is because endogenous explanatory variables predicted by the instruments may be close to collinear, which makes it difficult to separate the effect of each individual one. Stock and Yogo (2002) provide a framework that allows for testing the hypothesis of weak instruments in the case of up to three endogenous variables. Therefore, we instrument (in addition to $\sigma_{i t}$ ) for those two controls for which endogeneity is the most serious concern: high-tech capital and R\&D intensity. ${ }^{66}$ The results for all structural variables, including input skill intensity, are very similar to the previous specification - with the exception of high-tech capital that now has a larger coefficient. The $p$-values for the overidentification test is again well above the rejection level. Finally, instruments are close to the highest quality level according to the Stock and Yogo test. ${ }^{67}$ Altogether, the results reported in Table

\footnotetext{
${ }^{64}$ Our second stage estimation results do not depend on whether or not we use these additional instruments, but they contribute to instrument quality and provide additional overidentification restrictions.

${ }^{65}$ See, in particular, regression (3) in Table 4, which also uses $h_{i t}^{w}$ as dependent variable.

${ }^{66} \mathrm{R} \& \mathrm{D}$ intensity can be instrumented with one more time lag without losing an additional time period of observations, because the R\&D data include 1963.

${ }^{67}$ The null hypothesis is that instrument quality is below one of four levels. The last row of Table 6 reports the critical value for the highest quality level, corresponding to a maximum IV bias of 5\% because of weak instruments. The critical value for the
} 
6 support to role of ITSC as an additional - up to now neglected - phenomenon in the SBTC literature that can explain a large fraction of skill upgrading in U.S. manufacturing.

\section{Conclusion}

While intermediate inputs account for more than half of a final product's value, intersectoral linkages have been ignored as a source of skill bias. Existing empirical work, focusing on within-sector skill bias, cannot account for the full scope of skill upgrading in recent decades. This paper extends the standard SBTC framework, adding intersectoral skill complementarities that operate through the use of intermediate products. In this setup, SBTC in one sector increases skill demand in many other sectors, which delivers a multiplier that reinforces skill demand along the production chain.

In the empirical section, we analyze input skill intensity, which measures the skills embedded in a sector's intermediate inputs. This serves as a proxy for the skill bias in intermediate production. We construct this variable by combining product flows from input-output tables with worker characteristics from the NBER Manufacturing Industry Database. Input skill intensity correlates strongly with final production skills. This finding is robust to the inclusion of numerous control variables previously suggested in the SBTC literature, as well as to using alternative measures of input skill intensity. The presented evidence implies intersectoral technology-skill complementarity (ITSC) that amplifies within-sector skill bias and spreads its impact across sectors. This finding does not come as a surprise. It combines the well-documented findings of a technology-skill complementarity within sectors with technological spillovers across sectors.

Empirical evidence suggests that ITSC works through product innovation. We show that product innovation is more pronounced in sectors producing differentiated goods. Thus, downstream industries using differentiated intermediates purchase relatively more embedded innovation. We then show that ITSC is stronger among sectors linked through more differentiated intermediates.

ITSC contributes in an important way to the observed increase in skill demand over the last decades. Our estimation strategy follows from a framework that has been previously used in the skill demand context. Feenstra and Hanson (1999) apply the same method to study the importance of IT capital and outsourcing for skill upgrading. Our setup controls for these, and in addition for other previously suggested drivers of SBTC: capital equipment and R\&D intensity. To this familiar list we add input skill intensity, using instruments to account for endogeneity concerns. The results reproduce previous findings for the control variables - together they can account for about half of the rise in skill demand. ITSC closes much of the remaining empirical gap. Its contribution is large, explaining roughly one third of increasing skill demand in U.S. manufacturing between 1967 and 1992. This is similar to the importance of IT capital and more than twice the one of outsourcing or R\&D. Remarkably, ITSC is orthogonal to within-sector drivers of skill upgrading, which underlines its role as a new phenomenon in the SBTC literature.

Interestingly, the multiplier identified in this paper can also help to reconcile theoretical SBTC models with the data. In order to generate the observed upward-sloping relationship between relative skill supply second quality level (maximum IV bias of 10\%) is 10.01 for column 3 . 
and the skill premium, these models need an unrealistically high elasticity of substitution between skilled and unskilled labor. ${ }^{68}$ The multiplier effect identified here can resolve this issue: Skill-complementary technology affects not only the sectors that use it directly, but also has an indirect impact on downstream sectors that handle the corresponding products as intermediates. Therefore, smaller elasticities are sufficient to generate increasing skill premia in response to growing supply of skilled labor.

The present paper documents the novel stylized fact of intersectoral technology-skill complementarity in U.S. manufacturing, focusing on the period 1967-92. Unfortunately, compatible 4-digit input-output data and worker characteristics are not readily available beyond the 1990s. More recent data may modify some of our findings, since we expect outsourcing to play an increasingly important role. Another topic for further investigation is whether ITSC is a broad phenomenon, extending to linkages beyond the manufacturing sector. In addition, ITSC provides a new angle for the international flow of technology. Skill biased "Northern" technology may be inappropriate in the "South" not only because it involves the handling of complex machinery, but also because it is embedded in skill-intensive supply chains.

\section{Appendix}

\section{A.1 Solving the Model}

\section{Production side}

Firms' optimization with respect to $H_{i}$ and $L_{i}$ yields the relative demand for skilled workers shown in (7). The FOC with respect to $\bar{x}_{i}$ gives sector $i$ 's demand for effective units of each intermediate input $j, x_{i j}$, as a function of total output and goods prices:

$$
x_{i j}=\bar{x}_{i}=\frac{(1-\alpha) p_{i} Y_{i}}{\sum_{j \neq i} p_{j} a_{i j}}, \forall j
$$

In the following, we use these conditions to derive the demand for each factor and the marginal cost of production, which equals the product price under perfect competition. Rearranging (7) and substituting for $H_{i}$ in (1) yields

$$
L_{i}=\left(\frac{w_{L}}{1-\gamma}\right)^{-\epsilon} \Omega_{i}^{\epsilon}\left(\bar{x}_{i}\right)^{-\frac{1-\alpha}{\alpha}}\left(Y_{i}\right)^{\frac{1}{\alpha}}
$$

and similarly for $H_{i}$ :

$$
H_{i}=\left(\frac{w_{H}}{\gamma}\right)^{-\epsilon}\left(T_{i} \sigma_{i}^{\phi}\right)^{\epsilon-1} \Omega_{i}^{\epsilon}\left(\bar{x}_{i}\right)^{-\frac{1-\alpha}{\alpha}}\left(Y_{i}\right)^{\frac{1}{\alpha}}
$$

\footnotetext{
${ }^{68}$ See for example Acemoglu (1998, 2002b, 2007); Acemoglu and Zilibotti (2001), and in particular Acemoglu (2002a). These models require an elasticity larger than 2, while empirical studies commonly find smaller values (see Angrist, 1995; Ciccone and Peri, 2005).
} 
where $\Omega_{i}$ is the cost of the $H_{i}-L_{i}$ labor composite, given by

$$
\Omega_{i}=\left[\gamma^{\epsilon} w_{H}^{1-\epsilon}\left(T_{i} \sigma_{i}^{\phi}\right)^{\epsilon-1}+(1-\gamma)^{\epsilon} w_{L}^{1-\epsilon}\right]^{\frac{1}{1-\epsilon}}
$$

The next steps lead to factor demand as linear functions of $Y_{i}$. Multiplying (A.2) and (A.3) by the respective wages and adding up yields the total cost of labor in sector $i$ :

$$
w_{L} L_{i}+w_{H} H_{i}=\Omega_{i}\left(\bar{x}_{i}\right)^{-\frac{1-\alpha}{\alpha}}\left(Y_{i}\right)^{\frac{1}{\alpha}}
$$

The FOC of producers' optimization also imply the standard result that the expenditure share for labor is $\alpha$, i.e., $w_{L} L_{i}+w_{H} H_{i}=\alpha p_{i} Y_{i}$. Plugging this into (A.1) gives

$$
\frac{w_{L} L_{i}+w_{H} H_{i}}{\bar{p}_{i} \bar{x}_{i}}=\frac{\alpha}{(1-\alpha)}
$$

where $\bar{p}_{i} \equiv \sum_{j \neq i} a_{i j} p_{j}$ is the effective (or weighted average) input price. Plugging (A.6) into (A.5) yields the demand for effective units of each input as a function of factor prices and output:

$$
\bar{x}_{i}=\frac{1-\alpha}{\bar{p}_{i}}\left(\frac{\bar{p}_{i}}{1-\alpha}\right)^{1-\alpha}\left(\frac{\Omega_{i}}{\alpha}\right)^{\alpha} Y_{i}
$$

Using this result together with (A.2) gives the demand for low-skilled labor $L_{i}$; and together with (A.3) for high-skilled labor $H_{i}$, as functions of factor prices and output:

$$
\begin{array}{r}
L_{i}=\alpha\left(\frac{1-\gamma}{w_{L}}\right)^{\epsilon} \Omega_{i}^{\epsilon-1}\left(\frac{\bar{p}_{i}}{1-\alpha}\right)^{1-\alpha}\left(\frac{\Omega_{i}}{\alpha}\right)^{\alpha} Y_{i} \\
H_{i}=\alpha\left(\frac{\gamma}{w_{H}}\right)^{\epsilon}\left(T_{i} \sigma_{i}^{\phi}\right)^{\epsilon-1} \Omega_{i}^{\epsilon-1}\left(\frac{\bar{p}_{i}}{1-\alpha}\right)^{1-\alpha}\left(\frac{\Omega_{i}}{\alpha}\right)^{\alpha} Y_{i}
\end{array}
$$

We can now derive the total cost of production, $T C_{i}$, by multiplying (A.7) - (A.9) with the corresponding factor prices and adding up. ${ }^{69}$

$$
T C_{i}=\left(\frac{\bar{p}_{i}}{1-\alpha}\right)^{1-\alpha}\left(\frac{\Omega_{i}}{\alpha}\right)^{\alpha} Y_{i}
$$

Due to perfect competition within sectors and constant returns to scale in production, representative firms make zero profits, which implies $p_{i} Y_{i}=T C_{i}$. Therefore, the price of good $i$ is given by

$$
p_{i}=\left(\frac{\bar{p}_{i}}{1-\alpha}\right)^{1-\alpha}\left(\frac{\Omega_{i}}{\alpha}\right)^{\alpha} .
$$

\footnotetext{
${ }^{69}$ Recall that $\bar{x}_{i}$ also reflects the total amount of inputs used in sector $i$, which follows from (3) and the normalization $\sum_{j \neq i} a_{i j}=$ 1. The total cost of intermediate inputs is equal to $\sum_{j \neq i} p_{j} X_{i j}=\sum_{j \neq i} p_{j} a_{i j} \bar{x}_{i}=\bar{p}_{i} \bar{x}_{i}$, i.e., the weighted average input price multiplied by the total amount of inputs used.
} 
All agents have the same consumption preferences, independent of their skill level. Skill-specific wages $w_{L}$ and $w_{H}$ are the only source of income. There is no investment. A representative consumer draws utility from the consumption $c_{i}$ of all $N$ goods according to the Cobb-Douglas preferences

$$
u\left(\left\{c_{i}\right\}_{i=1}^{N}\right)=\exp \left(\sum_{i=1}^{N} \ln c_{i}\right) .
$$

This formulation of utility is convenient because it delivers constant and equal final expenditure shares. Let $c_{L, i}$ and $c_{H, i}$ denote labor-type specific consumption of good $i$. Low-skilled and high-skilled individuals maximize (A.12) subject to their budget constraints $\sum_{i=1}^{N} p_{i} c_{L, i} \leq w_{L}$ and $\sum_{i=1}^{N} p_{i} c_{H, i} \leq w_{H}$, respectively. This yields the skill-specific demand functions

$$
c_{L, i}=\frac{w_{L}}{N p_{i}} \quad \text { and } \quad c_{H, i}=\frac{w_{H}}{N p_{i}}
$$

Let $C_{i}=L c_{L, i}+H c_{H, i}$ denote total final demand, and $X_{\bullet i}=\sum_{j \neq i} X_{j i}$ total intermediate demand for good $i$. We can now specify the three market clearing constraints that the economy faces:

$$
\begin{gathered}
L=\sum_{i=1}^{N} L_{i} \\
H=\sum_{i=1}^{N} H_{i}
\end{gathered}
$$

and

$$
Y_{i}=C_{i}+X_{\bullet i}, \forall i
$$

The first two constraints assume that both types of labor are fully employed. The third constraint says that each sector's output is completely used up in final consumption and as an intermediate input for production in other sectors.

\section{Equilibrium with symmetric technology}

We can now derive the quantities for the symmetric case described in definition 1. First, (4) becomes $\sigma_{i}=1 /(N-1) \sum_{j \neq i} A_{j}$, which together with (5) implies $A_{i}=A, \forall i{ }^{70}$ Plugging this result into (A.4) yields $\Omega_{i}=\Omega, \forall i$. Next, using $\bar{p}_{i}=1 /(N-1) \sum_{j \neq i} p_{j}$ in (A.11) implies $p_{i}=p, \forall i{ }^{71}$ Consequently,

\footnotetext{
${ }^{70}$ The proof is by contradiction. Suppose $A_{i} \neq A_{j}$ for at least one pair $j \neq i$. We can order the $A_{i}$ such that (without loss of generality) $A_{1}>A_{2} \geq A_{3} \geq \ldots \geq A_{N}$. Then $A_{1}=\left(\sum_{j \neq 1} 1 /(N-1) A_{j}\right)^{\phi} T<A_{1}^{\phi} T$ and therefore $A_{1}^{1-\phi}<T$. Similar steps lead to $A_{N}^{1-\phi}>T$. Consequently, $A_{1}<A_{N}$, which contradicts the ordering.

${ }^{71}$ To prove this, define the average price as $p=[(N-1) / N] \bar{p}_{i}+[1 / N] p_{i}$ and suppose that sector $i$ charges a higher price, $p_{i}>p$. Then $\bar{p}_{i}<p$, which implies that sector $i$ has a lower intermediate input price, but charges more for its final product than
} 
$\bar{p}_{i}=p, \forall i$. Because of price symmetry, final demand (A.13) is also symmetric, and so are factor demands (A.7)-(A.9). Thus, $L_{i}=L / N, H_{i}=H / N$, and $Y_{i}=Y / N$, where $Y$ is total (intermediate and final) output of the economy. Dividing (A.9) by (A.8) in the symmetric case gives equation (11).

Finally, we show that goods markets clear. We use the superscripts $D$ for demand and $S$ for supply. Total demand for each good $i$ has a final and an intermediate component: $Y_{i}^{D}=C_{i}+X_{\bullet}$. The former derives from (A.13) and is given by

$$
C_{i}=c_{L, i} L+c_{H, i} H=\frac{w_{L} L+w_{H} H}{N p},
$$

while the latter is composed of the demand for sector $i$ 's output from all other $N-1$ sectors:

$$
X_{\bullet i}=\sum_{j \neq i} \frac{1}{N-1} \bar{x}_{j}=\left(\frac{p}{1-\alpha}\right)^{1-\alpha}\left(\frac{\Omega}{\alpha}\right)^{\alpha} \frac{1-\alpha}{p(N-1)} \sum_{j \neq i} Y_{j}^{S}=\frac{(1-\alpha)}{N-1} \sum_{j \neq i} Y_{j}^{S}
$$

where the first equality follows from (3) and the last one from (A.11). Next, we replace $Y_{j}^{S}$ using the symmetric expression for the expenditure share, $\alpha p Y_{j}^{S}=\left(w_{L} L+w_{H} H\right) / N$ in all sectors $j \neq i$. Therefore, total demand for each good $i$ is given by

$$
Y_{i}^{D}=C_{i}+X_{\bullet i}=\frac{w_{L} L+w_{H} H}{N p}+\frac{(1-\alpha)}{\alpha(N-1)} \sum_{j \neq i} \frac{w_{L} L+w_{H} H}{N p}=\frac{1}{\alpha} \frac{w_{L} L+w_{H} H}{N p} .
$$

Total demand for $i$ is thus a multiple $1 / \alpha$ of the corresponding final demand. With $\alpha=0.5$, doubling final demand means quadrupling total demand. Under perfect competition, total sales in each sector $i$ equal total expenditures for labor and intermediates:

$$
p_{i} Y_{i}^{S}=w_{L} L_{i}+w_{H} H_{i}+\sum_{j \neq i} p_{j} X_{i j}
$$

where the last term is equal to $\bar{p}_{i} \bar{x}_{i}$. Under symmetry, and using (A.7) together with the labor expenditure share to replace $\bar{p}_{i} \bar{x}_{i},($ A.20) yields total supply for each $i$

$$
Y_{i}^{S}=\frac{1}{\alpha} \frac{w_{L} L+w_{H} H}{N p}
$$

which equals total demand given by (A.19).

\section{A.2 Data Sources and Construction of Variables}

\section{Product innovation}

Scherer (1982) provides data on R\&D expenditures broken down into product and process innovation for the economy average, therefore making positive profits. This would attract competitors charging lower prices until $p_{i}=p$. 
36 manufacturing sectors, broadly equivalent to the 2-digit level. In this context, a new process is defined as a technical improvement in a firm's own production methods, while a new product is an improvement sold to other business enterprises or consumers. Scherer uses data from the Federal Trade Commission's Line of Business survey for 1974 to construct a match between industrial invention patents and the underlying R\&D expenditures. He also derives, for each patent, its industry of origin and industries using the invention. Based on these data, Scherer implements a methodology first proposed by Schmookler (1966): Constructing a matrix similar to an input-output table, with industries performing $R \& D$ and originating inventions comprising the rows. Industries (including end consumers) that use those inventions comprise the columns. Each element in the matrix represents the flow of technology from an originating industry to a using one. Diagonal elements indicate process technology. We use this table to derive, for each industry, its share of R\&D spent for product innovation, $\pi_{i}^{\text {prod }}$, as the sum of off-diagonal elements divided by total R\&D expenditures (row-sum).

\section{Additional control variables}

The capital measure in efficiency units used by Krusell et al. (2000) is only available at the aggregate U.S. level. Thus, we use the 4-digit SIC figures from the Manufacturing Industry Database for real capital equipment and structures. ${ }^{72}$ The National Science Foundation (NSF) provides company and other (except Federal) research and development (R\&D) expenditures as a percentage of sales by industry. This $R \& D$ proportion is commonly referred to as R\&D intensity. ${ }^{73}$ The NSF data cover 24 industries that we match to the 358 industries of our sample. ${ }^{74}$ The weighted mean of R\&D intensity for our sample increases from 2.12 percent in 1963 to 3.28 percent in 1992.

In order to control for computer equipment and other high-technology capital, we use detailed data on private nonresidential fixed assets from the BEA. These data distinguish capital by asset type for 21 (approximately two-digit) NAICS manufacturing industries, which we match to the 358 industries of our panel. We derive the real net capital stock by asset type and industry (in 2000 dollars) from the current-cost capital stock and the chain-type quantity index. Following Berndt, Morrison, and Rosenblum (1992), who use an earlier version of this dataset, we define high-technology capital to include office, computing and accounting machinery; communications equipment; scientific and engineering instruments; and photocopy and related equipment. From this number we calculate the share of high-technology capital in the total capital stock for each industry $(H T / K)$. The weighted average of this broad measure increases from 1.2 percent in 1967 to 3.2 percent in 1982, and 6.0 percent in 1992. A frequently used, more narrowly defined measure includes only the share of office, computing and accounting equipment in the capital stock $(O C A M / K)$. This variable is 0.4 percent in 1967, 0.8 percent in 1982, and then increases to 2.0 percent in 1992.

Feenstra and Hanson (1999) derive, for each 4-digit SIC industry, a proxy for imported intermediate

\footnotetext{
${ }^{72}$ See Bartelsman and Grey (1996) for a documentation of these data and the corresponding investment deflators.

${ }^{73} \mathrm{See}$, for example, Autor et al. (1998), who work with the same NSF data as used here.

${ }^{74}$ The corresponding crosswalk from the 24 NSF industries to the 358 SIC industries of our sample is available upon request. Due to missing observations in the NSF data, several imputations and interpolations were required.
} 
inputs from trade data. Expressing this measure relative to total expenditure on non-energy intermediates in each industry gives their broad measure of foreign outsourcing. The narrow measure considers only inputs that are purchased from the same 2-digit SIC industry as the good being produced. This restricts attention to the outsourcing of production activities that could have been performed by the respective industry within the United States. The broad measure includes all imported intermediates. We calculate both measures of outsourcing for the years and sectors included in our sample, using data on U.S. imports and exports by 4-digit SIC industries from the Center for International Data at UC Davis together with the above described input-output data. ${ }^{75}$ The weighted averaged broad (narrow) measure increases from 4.4 (2.4) percent in 1967 to 8.6 (3.9) percent in 1982 and 13.4 (6.6) percent in 1992.

\footnotetext{
${ }^{75}$ We construct a crosswalk to match the 450 manufacturing industries from the trade database to the 358 industries of our sample. The correspondences are available upon request. We follow Feenstra and Hanson, using nominal input shares when calculating the outsourcing measure. Our results do not change when using price-adjusted input shares instead.
} 


\section{References}

Acemoglu, D. (1998). Why Do New Technologies Complement Skills? Directed Technical Change And Wage Inequality. Quarterly Journal of Economics 113(4), 1055-1089.

Acemoglu, D. (2002a). Directed Technical Change. Review of Economic Studies 69(4), 781-809.

Acemoglu, D. (2002b). Technical Change, Inequality, and the Labor Market. Journal of Economic Literature 40(1), $7-72$.

Acemoglu, D. (2007). Equilibrium Bias of Technology. Econometrica 75(5), 1371-1409.

Acemoglu, D. and F. Zilibotti (2001). Productivity Differences. Quarterly Journal of Economics 116(2), 563-606.

Angrist, J. D. (1995). The Economic Returns to Schooling in the West Bank and Gaza Strip. American Economic Review 85(5), 1065-87.

Arellano, M. and S. R. Bond (1991). Some Tests of Specification for Panel Data: Monte Carlo Evidence and an Application to Employment Equations. Review of Economic Studies 58(2), 277-297.

Autor, D. H., L. F. Katz, and M. S. Kearney (2008). Trends in U.S. Wage Inequality: Revising the Revisionists. Review of Economics and Statistics 90(2), 300-323.

Autor, D. H., L. F. Katz, and A. B. Krueger (1998). Computing Inequality: Have Computers Changed the Labor Market? Quarterly Journal of Economics 113(4), 1169-1214.

Autor, D. H., F. Levy, and R. J. Murnane (2003). The Skill Content of Recent Technological Change: An Empirical Exploration. Quarterly Journal of Economics 118(4), 1279-1333.

Bartel, A. P. and F. Lichtenberg (1987). The Comparative Advantage of Educated Workers in Implementing New Technology. Review of Economics and Statistics 69(1), 1-11.

Bartelsman, E. J. and W. Grey (1996). The NBER Manufacturing Productivity Database. NBER Technical Working Paper 205.

Basu, S. (1995). Intermediate Goods and Business Cycles: Implications for Productivity and Welfare. American Economic Review 85(3), 512-531.

Becker, R., J. Haltiwanger, R. Jarmin, S. Klimek, and D. Wilson (2006). Micro and Macro Data Integration: The Case of Capital. In D. W. Jorgenson, J. S. Landefeld, and W. D. Nordhaus (Eds.), A New Architecture for the U.S. Nation Accounts. University of Chicago Press.

Berman, E., J. Bound, and Z. Griliches (1994). Changes in the Demand for Skilled Labor within U.S. Manufacturing: Evidence from the Annual Survey of Manufacturers. Quarterly Journal of Economics 109(2), 367-397.

Berman, E., J. Bound, and S. Machin (1998). Implications of Skill-Biased Technological Change: International Evidence. Quarterly Journal of Economics 113(4), 1245-1279.

Berndt, E. R., C. J. Morrison, and L. S. Rosenblum (1992). High-Tech Capital Formation and Labor Composition in U.S. Manufacturing Industries: An Exploratory Analysis. NBER Working Paper 4010.

Bertrand, M., E. Duflo, and S. Mullainathan (2004). How Much Should We Trust Differences-in-Differences Estimates? Quarterly Journal of Economics 119(1), 249-275.

Blalock, G. and P. J. Gertler (2008). Welfare Gains from Foreign Direct Investment through Technology Transfer to Local Suppliers. Journal of International Economics 74(2), 402-421. 
Blanchard, O. and M. Kremer (1997). Disorganization. Quarterly Journal of Economics 112(4), 1091-1126.

Bound, J. and G. Johnson (1992). Changes in the Structure of Wages in the 1980s: An Evaluation of Alternative Explanations. American Economic Review 82(3), 371-392.

Bresnahan, T. F., E. Brynjolfsson, and L. M. Hitt (2002). Information Technology, Workplace Organization and the Demand for Skilled Labor: Firm-Level Evidence. Quarterly Journal of Economics 117(1), 339-376.

Card, D. and J. E. DiNardo (2002). Skill-Biased Technological Change and Rising Wage Inequality: Some Problems and Puzzles. Journal of Labor Economics 20(4), 733-783.

Ciccone, A. (2002). Input Chains and Industrialization. Review of Economic Studies 69, 565-587.

Ciccone, A. and G. Peri (2005). Long-run Substitutability Between More and Less Educated Workers: Evidence from U.S. States 1950-1990. Review of Economics and Statistics 87(4), 652-663.

DiNardo, J. E. and J.-S. Pischke (1997). The Returns to Computer Use Revisited: Have Pencils Changed the Wage Structure Too? Quarterly Journal of Economics 112(1), 291-303.

Doms, M., T. Dunne, and K. R. Troske (1997). Workers, Wages, and Technology. Quarterly Journal of Economics 112(1), 253-290.

Epifani, P. and G. Gancia (2006). Increasing Returns, Imperfect Competition, and Factor Prices. Review of Economics and Statistics 88(4), 583-598.

Feenstra, R. C. (2004). Advanced International Trade: Theory and Evidence. Princeton, N.J.: Princeton University Press.

Feenstra, R. C. and G. H. Hanson (1999). The Impact of Outsourcing and High-Technology Capital on Wages: Estimates for the United States, 1979-1990. Quarterly Journal of Economics 114(3), 907-940.

Goldin, C. and L. F. Katz (1998). The Origins of Technology-Skill Complementarity. Quarterly Journal of Economics 113(3), 693-732.

Griliches, Z. (1969). Capital-Skill Complementarity. Review of Economics and Statistics 51(4), 465-468.

Hirschman, A. O. (1958). The Strategy of Economic Development. New Haven, CT: Yale University Press.

Jones, C. I. (2009). Intermediate Goods and Weak Links: A Theory of Economic Development. U.C. Berkeley Working Paper.

Katz, L. F. and D. H. Autor (1999). Changes in the Wage Structure and Earnings Inequality. In O. Ashenfelter and D. E. Card (Eds.), Handbook of Labor Economics, Volume 3, Chapter 26, pp. 1463-1555. Amsterdam, North Holland: Elsevier.

Katz, L. F. and K. M. Murphy (1992). Changes in Relative Wages, 1963-1987: Supply and Demand Factors. Quarterly Journal of Economics 107(1), 35-78.

Keller, W. (2004). International Technology Diffusion. Journal of Economic Literature 42(3), 752-782.

Kim, H. Y. (1992). The Translog Production Function and Variable Returns to Scale. Review of Economics and Statistics 74(3), 546-552.

Koo, J. (2005). Technology Spillovers, Agglomeration, and Regional Economic Development. Journal of Planning Literature 20(2), 99-115.

Krueger, A. B. (1993). How Computers Changed the Wage Structure: Evidence from Microdata, 1984-1989. Quarterly Journal of Economics 108(1), 33-60. 
Krusell, P., L. E. Ohanian, J.-V. Ríus-Rull, and G. L. Violante (2000). Capital-Skill Complementarity and Inequality: A Macroeconomics Analysis. Econometrica 68(5), 1029-1053.

Leamer, E. E. (1996). Wage Inequality from International Competition and Technological Change: Theory and Country Experience. American Economic Review 86(2), 309-314.

Leontief, W. (1936). Quantitative Input and Output Relations in the Economic System of the United States. Review of Economics and Statistics 18(3), 105-125.

Levy, F. and R. J. Murnane (1996). With What Skills are Computers a Complement? American Economic Review Papers and Proceedings 86(2), 258-262.

Machin, S. and J. van Reenen (1998). Technology and Changes in Skill Structure: Evidence from Seven OECD Countries. Quarterly Journal of Economics 113(4), 1215-1244.

Milgrom, P. and J. Roberts (1990). The Economics of Modern Manufacturing: Technology, Strategy, and Organization. American Economic Review 80(3), 511-528.

Nelson, R. R. and E. S. Phelps (1966). Investment in Humans, Technological Diffusion, and Economic Growth. American Economic Review 56(2), 69-75.

Nunn, N. (2007). Relationship-Specificity, Incomplete Contracts and the Pattern of Trade. Quarterly Journal of Economics 122(2), 569-600.

Pavcnik, N. (2003). What Explains Skill Upgrading in Less Developed Countries? Journal of Development Economics 71(2), 311-328.

Pavitt, K. (1984). Patterns of Technical Change: Towards a Taxonomy and a Theory. Research Policy 13(6), $342-373$.

Rauch, J. E. (1999). Networks versus Markets in International Trade. Journal of International Economics 48(1), 7-35.

Rodríguez-Clare, A. (1996). Multinationals, Linkages, and Economic Development. American Economic Review 86(4), 852-873.

Sanders, M. and B. ter Weel (2000). Skill-Biased Technical Change: Theoretical Concepts, Empirical Problems and a Survey of the Evidence. DRUID Working Papers.

Scherer, F. M. (1982). Inter-Industry Technology Flows in the United States. Research Policy 11(4), $227-245$.

Schmookler, J. (1966). Invention and Economic Growth. Cambridge, MA: Harvard University Press.

Staiger, D. and J. H. Stock (1997). Instrumental Variables Regression with Weak Instruments. Econometrica 65(3), 557-586.

Stock, J. H. and M. Yogo (2002). Testing for Weak Instruments in Linear IV Regressions. NBER Technical Working Paper 284.

Verhoogen, E. (2008). Trade, Quality Upgrading and Wage Inequality in the Mexican Manufacturing Sector. Quarterly Journal of Economics 123(2), 489-530.

Violante, G. L. (2006). Skill-Biased Technical Change. In L. Blume and S. Durlauf (Eds.), The New Palgrave Dictionary of Economics (2 ed.). Palgrave Macmillan.

White, H. (1982). Maximum Likelihood Estimation of Misspecified Models. Econometrica 50(1), 1-25.

Wood, A. (1998). Globalisation and the Rise in Labour Market Inequalities. Economic Journal 108(450), 1463-1482.

Wooldridge, J. M. (2002). Econometric Analysis of Cross Section and Panel Data. Cambridge, MA: MIT Press. 
Yi, K.-M. (2003). Can Vertical Specialization Explain the Growth of World Trade? Journal of Political Economy 111(1), 52-102.

Zhu, S. C. (2005). Can Product Cycles Explain Skill Upgrading? Journal of International Economics 66(1), 131-155. 


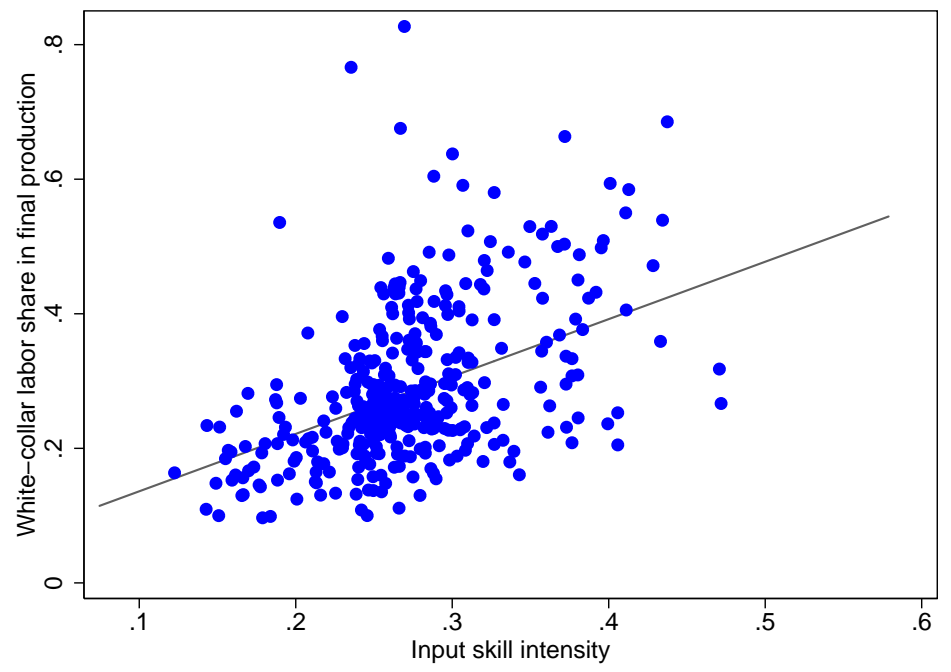

Figure 1: Skilled labor share in final production vs. input skill intensity

Notes: Data are for 358 U.S. manufacturing sectors in 1992. Input skill intensity is calculated as the weighted average share of white-collar workers employed in the production of a sector's intermediate inputs. Only inputs purchased outside a sector are taken into account. See Section 4 for a formal description and data sources, and Section 5 for regression results and robustness. 

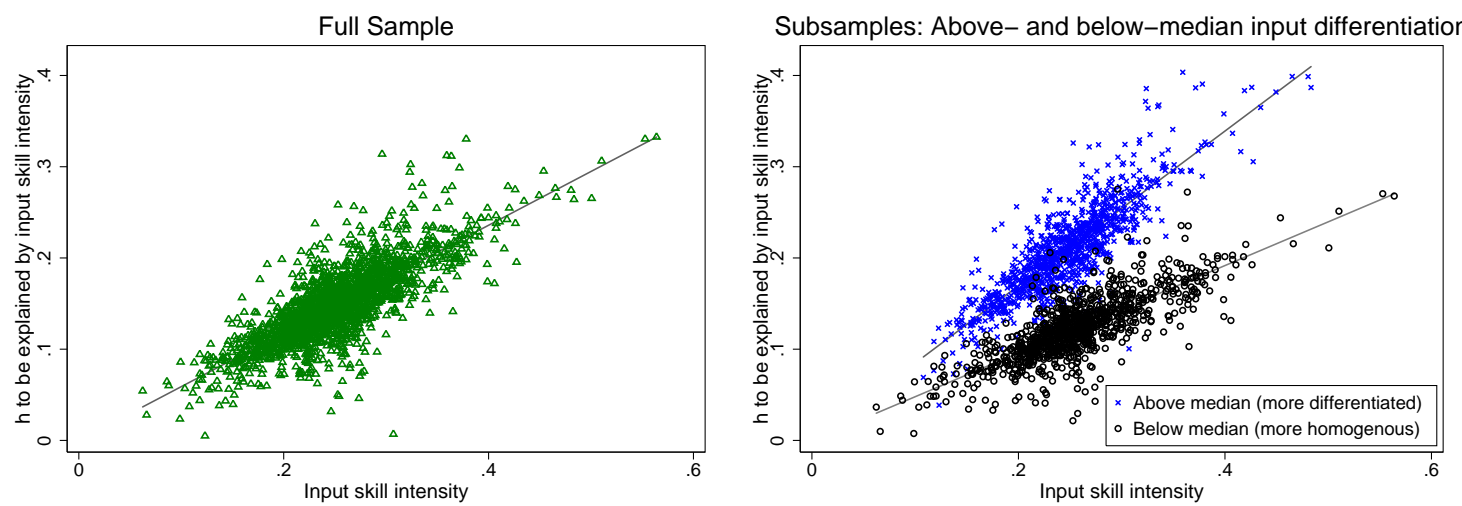

Figure 2: Partial scatter plots: Skilled labor share $\left(h_{i t}\right)$ vs. input skill intensity $\left(\sigma_{i t}\right)$

Notes: The measure of input differentiation is calculated as in (13), yielding a median of .52. The vertical axis shows $h_{i t}-\left(\hat{\alpha}_{i}+\hat{\alpha}_{t}+\hat{\gamma} \mathbb{T}_{i t}\right)$; notice that $\hat{\beta} \sigma_{i t}$ does not appear in this equation. In the left panel, coefficient estimates $\hat{\alpha}_{i}$, $\hat{\alpha}_{t}$, and $\hat{\gamma}$ are obtained by estimating (15) for the full sample (2089 obs.), with the controls $\mathbb{T}_{i t}$ comprising $k^{\text {struct }}, k^{\text {equip }}$, $H T / K, R \& D_{l a g}$, and $O S^{\text {narr }}$. In the right panel, the same methodology is applied for the two subsamples including sectors with above-median input differentiation (1040 obs.) and below-median input differentiation (1049 obs.).

Table 1: Correlations between input skill intensity and control variables

\begin{tabular}{|c|c|c|c|c|c|c|c|}
\hline \multirow[b]{3}{*}{ Measure } & \multirow{2}{*}{\multicolumn{2}{|c|}{$\begin{array}{l}\text { Input skill } \\
\text { intensity }\end{array}$}} & \multicolumn{3}{|c|}{ Capital } & \multirow{3}{*}{$\begin{array}{l}\mathrm{R} \& \mathrm{D} / \\
\text { sales } \\
R \& D_{l a g}\end{array}$} & \multirow{3}{*}{$\begin{array}{l}\text { Out- } \\
\text { sourcing } \\
O S^{\text {narr }}\end{array}$} \\
\hline & & & \multicolumn{2}{|c|}{ per worker } & \multirow{2}{*}{$\begin{array}{l}\text { High- } \\
\text { Tech } \\
H T / K\end{array}$} & & \\
\hline & $\sigma_{i}$ & $\sigma_{i}^{2 \mathrm{~d}}$ & $k^{\text {equip }}$ & $k^{\text {struct }}$ & & & \\
\hline$\sigma_{i}$ & 1 & & & & & & \\
\hline$\sigma_{i}^{2 \mathrm{~d}}$ & $.66^{* * *}$ & 1 & & & & & \\
\hline$k^{\text {equip }}$ & $.12 * * *$ & $.15^{* * *}$ & 1 & & & & \\
\hline$k^{\text {struct }}$ & $.05^{* *}$ & $.07 * * *$ & $.70 * * *$ & 1 & & & \\
\hline$H T / K$ & $.20 * * *$ & $.14 * * *$ & -.03 & -.01 & 1 & & \\
\hline$R \& D_{l a g}$ & $.18 * * *$ & $.13 * * *$ & -.01 & .03 & $.39 * * *$ & 1 & \\
\hline$O S^{\text {narr }}$ & $.13^{* * *}$ & $.11 * * *$ & $.05 * *$ & $.04 *$ & .03 & $.10 * * *$ & 1 \\
\hline
\end{tabular}

Notes: Reported numbers are pairwise correlation coefficients, controlling for sector and time fixed effects. Key: $* * *$ significant at $1 \%$;* $5 \%$; $10 \%$. 
Table 2: Final production skills, input skill intensity, and controls. Dependent variable is $h_{i t}$.

\begin{tabular}{|c|c|c|c|c|c|c|}
\hline \multirow[t]{2}{*}{ Input skill measure } & \multicolumn{4}{|c|}{ Baseline: $\sigma_{i}$} & \multirow{2}{*}{$\begin{array}{l}\sigma_{i}^{2 \mathrm{~d}} \\
(5)\end{array}$} & \multirow{2}{*}{$\begin{array}{l}\sigma_{i}^{w} \\
(6)\end{array}$} \\
\hline & $(1)$ & $(2)$ & $(3)$ & $(4)$ & & \\
\hline Input skill intensity: $\sigma_{i}$ & $\begin{array}{l}.834 * * * \\
(.156)\end{array}$ & $\begin{array}{l}.658 * * * \\
(.145)\end{array}$ & $\begin{array}{l}.558 * * * \\
(.126)\end{array}$ & $\begin{array}{l}.665^{* * * *} \\
(.066)\end{array}$ & $\begin{array}{l}.502 * * * \\
(.170)\end{array}$ & $\begin{array}{l}.548 * * * \\
(.148)\end{array}$ \\
\hline Structures per worker: $k^{\text {struct }}$ & & $\begin{array}{l}.259^{*} \\
(.134)\end{array}$ & $\begin{array}{l}.191 \\
(.117)\end{array}$ & $\begin{array}{l}.249 * * \\
(.120)\end{array}$ & $\begin{array}{l}.232^{*} \\
(.122)\end{array}$ & $\begin{array}{l}.175 \\
(.118)\end{array}$ \\
\hline Equipment per worker: $k^{\text {equip }}$ & & $\begin{array}{l}-.114 * \\
(.067)\end{array}$ & $\begin{array}{l}-.0992 \\
(.062)\end{array}$ & $\begin{array}{l}-.168 * * \\
(.070)\end{array}$ & $\begin{array}{l}-.103 \\
(.064)\end{array}$ & $\begin{array}{l}-.0687 \\
(.061)\end{array}$ \\
\hline High-Tech capital: $H T / K$ & & $\begin{array}{l}.716 * * * \\
(.134)\end{array}$ & $\begin{array}{l}.600 * * * \\
(.151)\end{array}$ & $\begin{array}{l}.410 * * * \\
(.125)\end{array}$ & $\begin{array}{l}.618 * * * \\
(.150)\end{array}$ & $\begin{array}{l}.614 * * * \\
(.153)\end{array}$ \\
\hline Office equipment: $O C A M / K$ & & $\begin{array}{l}-.0692 \\
(.294)\end{array}$ & $\begin{array}{l}.0102 \\
(.316)\end{array}$ & $\begin{array}{l}.0576 \\
(.324)\end{array}$ & $\begin{array}{l}.0371 \\
(.308)\end{array}$ & $\begin{array}{l}.016 \\
(.316)\end{array}$ \\
\hline $\mathrm{R} \& \mathrm{D}$ intensity $R \& D_{l a g}$ & & & $\begin{array}{l}.401 * * \\
(.163)\end{array}$ & $\begin{array}{l}.322 * \\
(.193)\end{array}$ & $\begin{array}{l}.461 * * * \\
(.158)\end{array}$ & $\begin{array}{l}.363 * * \\
(.163)\end{array}$ \\
\hline Outsourcing: $O S^{\text {narr }}$ & & & $\begin{array}{l}.146 * * * \\
(.050)\end{array}$ & $\begin{array}{l}.122 * * \\
(.051)\end{array}$ & $\begin{array}{l}.161 * * * \\
(.053)\end{array}$ & $\begin{array}{l}.139 * * * \\
(.048)\end{array}$ \\
\hline Sector fixed effects & yes & yes & yes & yes & yes & yes \\
\hline Time fixed effects & yes & yes & yes & no & yes & yes \\
\hline $\begin{array}{l}R^{2} \\
R^{2} \text { (within) } \\
\text { Observations }\end{array}$ & $\begin{array}{c}.97 \\
.50 \\
2148\end{array}$ & $\begin{array}{c}.98 \\
.55 \\
2148\end{array}$ & $\begin{array}{l}.98 \\
.57 \\
2089\end{array}$ & $\begin{array}{l}.98 \\
.56 \\
2089\end{array}$ & $\begin{array}{l}.98 \\
.56 \\
2083\end{array}$ & $\begin{array}{l}.98 \\
.57 \\
2089\end{array}$ \\
\hline
\end{tabular}

Notes: Clustered standard errors (by sector) in parentheses. Key: *** significant at 1\%; ** 5\%; * 10\%. All regressions are weighted by sectors' average share in total manufacturing employment 1967-92. 
Table 3: Input skill intensity with time-varying input shares. Dependent variable is $h_{i t}$.

\begin{tabular}{|c|c|c|c|c|c|}
\hline \multirow[t]{2}{*}{ Input skill measure } & \multicolumn{2}{|c|}{$\sigma_{i}$} & \multirow{2}{*}{$\begin{array}{l}\sigma_{i}^{2 \mathrm{~d}} \\
(3)\end{array}$} & \multicolumn{2}{|c|}{$S_{i}$} \\
\hline & (1) & (2) & & (4) & (5) \\
\hline \multicolumn{6}{|l|}{ Input skill intensity } \\
\hline Skill component: $\sigma_{i} / \sigma_{i}^{2 \mathrm{~d}}$ & $\begin{array}{l}.832 * * * \\
(.150)\end{array}$ & $\begin{array}{l}.562 * * * \\
(.124)\end{array}$ & $\begin{array}{l}.511 * * * \\
(.161)\end{array}$ & & \\
\hline Input mix component: $\tau_{i} / \tau_{i}^{2 \mathrm{~d}}$ & $\begin{array}{l}.110 \\
(.077)\end{array}$ & $\begin{array}{l}.068 \\
(.061)\end{array}$ & $\begin{array}{l}-.011 \\
(.079)\end{array}$ & & \\
\hline Covariance component: $\rho_{i} / \rho_{i}^{2 \mathrm{~d}}$ & $\begin{array}{l}.725^{*} \\
(.389)\end{array}$ & $\begin{array}{l}.236 \\
(.394)\end{array}$ & $\begin{array}{l}.224 \\
(.466)\end{array}$ & & \\
\hline All together: $S_{i}=\sigma_{i}+\tau_{i}+\rho_{i}$ & & & & $\begin{array}{l}.189 * * * \\
(.059)\end{array}$ & $\begin{array}{l}.325^{* * *} \\
(.049)\end{array}$ \\
\hline Controls & no & yes & yes & yes & yes \\
\hline $\begin{array}{l}\text { Sector fixed effects } \\
\text { Time fixed effects }\end{array}$ & $\begin{array}{l}\text { yes } \\
\text { yes }\end{array}$ & $\begin{array}{l}\text { yes } \\
\text { yes }\end{array}$ & $\begin{array}{l}\text { yes } \\
\text { yes }\end{array}$ & $\begin{array}{l}\text { yes } \\
\text { yes }\end{array}$ & $\begin{array}{l}\text { yes } \\
\text { no }\end{array}$ \\
\hline $\begin{array}{l}R^{2} \\
R^{2} \text { (within) } \\
\text { Observations }\end{array}$ & $\begin{array}{l}.97 \\
.51 \\
2090\end{array}$ & $\begin{array}{c}.98 \\
.57 \\
2089\end{array}$ & $\begin{array}{c}.98 \\
.56 \\
2083\end{array}$ & $\begin{array}{l}.97 \\
.56 \\
2089\end{array}$ & $\begin{array}{l}.97 \\
.53 \\
2089\end{array}$ \\
\hline
\end{tabular}

Notes: Clustered standard errors (by sector) in parentheses. Key: *** significant at 1\%;**5\%; $10 \%$. All regressions are weighted by sectors' average share in total manufacturing employment 1967-92. Controls include the following variables: Structures per worker $\left(k^{\text {struct }}\right)$, equipment per worker $\left(k^{\text {equip }}\right)$, high-tech capital $(H T / K)$, office and computer capital $(O C A M / K)$, R\&D intensity $\left(R \& D_{l a g}\right)$, and outsourcing $\left(O S^{\text {narr }}\right)$. 
Table 4: Robustness analysis. Dependent variable is $h_{i}$.

\begin{tabular}{|c|c|c|c|c|c|}
\hline \multirow[t]{4}{*}{ Input skill measure } & \multicolumn{2}{|c|}{$\sigma_{i}$} & \multirow{2}{*}{$\frac{\sigma_{i}^{w}}{(3)^{\ddagger}}$} & \multicolumn{2}{|c|}{$\sigma_{i}^{2 \mathrm{~d}}$} \\
\hline & (1) & (2) & & (4) & (5) \\
\hline & Changes & Additional & Wage & 1967 & 1992 \\
\hline & & Controls & bill & only & only \\
\hline Input skill intensity: $\sigma_{i} / \sigma_{i}^{2 \mathrm{~d}} / \sigma_{i}^{w}$ & $\begin{array}{l}.621 * * * \\
(.062)\end{array}$ & $\begin{array}{l}.468 * * * \\
(.123)\end{array}$ & $\begin{array}{l}.574 * * * \\
(.201)\end{array}$ & $\begin{array}{l}.562 * \\
(.324)\end{array}$ & $\begin{array}{l}.467 * * * \\
(.139)\end{array}$ \\
\hline Structures per worker: $k^{\text {struct }}$ & $\begin{array}{l}.255^{*} \\
(.136)\end{array}$ & $\begin{array}{l}.291 * * \\
(.121)\end{array}$ & $\begin{array}{l}.353 * * * \\
(.135)\end{array}$ & $\begin{array}{l}-.557 \\
(1.317)\end{array}$ & $\begin{array}{l}.941 * * * \\
(.337)\end{array}$ \\
\hline Equipment per worker: $k^{\text {equip }}$ & $\begin{array}{l}-.0872 \\
(.090)\end{array}$ & $\begin{array}{l}-.107 * \\
(.064)\end{array}$ & $\begin{array}{l}-.266^{* * *} \\
(.090)\end{array}$ & $\begin{array}{l}.580 \\
(1.442)\end{array}$ & $\begin{array}{l}-.383 * * \\
(.176)\end{array}$ \\
\hline Office equipment: $O C A M / K$ & $\begin{array}{l}.107 \\
(.165)\end{array}$ & $\begin{array}{l}.588 \\
(.380)\end{array}$ & $\begin{array}{l}.481 \\
(.492)\end{array}$ & $\begin{array}{l}3.884 * * * \\
(1.306)\end{array}$ & $\begin{array}{l}4.637 * * * \\
(.460)\end{array}$ \\
\hline $\begin{array}{l}\text { High-Tech capital: difference } \\
\qquad(H T / K-O C A M / K)\end{array}$ & $\begin{array}{l}.124 \\
(.109)\end{array}$ & $\begin{array}{l}.579 * * * \\
(.152)\end{array}$ & $\begin{array}{l}.490 * * * \\
(.186)\end{array}$ & $\begin{array}{l}4.238 * * * \\
(.898)\end{array}$ & $\begin{array}{l}2.011 * * * \\
(.497)\end{array}$ \\
\hline $\mathrm{R} \& \mathrm{D}$ intensity $R \& D_{\text {lag }}$ & $\begin{array}{l}.323 * * \\
(.161)\end{array}$ & $\begin{array}{l}.268 \\
(.165)\end{array}$ & $\begin{array}{l}.468 * * * \\
(.181)\end{array}$ & $\begin{array}{l}1.077 \\
(1.027)\end{array}$ & $\begin{array}{l}.144 \\
(.364)\end{array}$ \\
\hline $\begin{array}{l}\text { Outsourcing: } O S^{\text {narr }} \\
\text { (narrow) }\end{array}$ & $\begin{array}{l}.0651^{*} \\
(.039)\end{array}$ & $\begin{array}{l}.159 * * * \\
(.045)\end{array}$ & $\begin{array}{l}.157^{* *} \\
(.069)\end{array}$ & $\begin{array}{l}-.650 * * \\
(.313)\end{array}$ & $\begin{array}{l}.0768 \\
(.100)\end{array}$ \\
\hline $\begin{array}{l}\text { Outsourcing (broad): difference } \\
\quad\left(O S^{\text {broad }}-O S^{\text {narr }}\right)\end{array}$ & & $\begin{array}{l}.0944^{*} \\
(.055)\end{array}$ & & $\begin{array}{l}-.0369 \\
(.570)\end{array}$ & $\begin{array}{l}.0781 \\
(.129)\end{array}$ \\
\hline Many inputs: $I_{i}^{n_{i}>\bar{n}}$ & & $\begin{array}{l}.00177 \\
(.005)\end{array}$ & & $\begin{array}{l}.00892 \\
(.026)\end{array}$ & $\begin{array}{l}.0352 * * * \\
(.012)\end{array}$ \\
\hline Input variety: $\left(1-H_{i}\right)$ & & $\begin{array}{l}-.00155 \\
(.014)\end{array}$ & & $\begin{array}{l}-.0837 \\
(.107)\end{array}$ & $\begin{array}{l}.0385 \\
(.042)\end{array}$ \\
\hline Relative wage: $\ln \left(w_{H, i} / w_{L, i}\right)$ & & $\begin{array}{l}-.0493 * * * \\
(.017)\end{array}$ & & & \\
\hline Real shipments: $\ln \left(Y_{i}\right)$ & & $\begin{array}{l}.00912 * * \\
(.004)\end{array}$ & & & \\
\hline Value added share & & $\begin{array}{l}.0330 * \\
(.017)\end{array}$ & & & \\
\hline Sector fixed effects & no & yes & yes & no & no \\
\hline Time fixed effects & no & yes & yes & no & no \\
\hline$R^{2}$ & .17 & .98 & .97 & .24 & .71 \\
\hline$R^{2}$ (within) & - & .59 & .55 & - & - \\
\hline Observations & 1731 & 2089 & 2089 & 328 & 356 \\
\hline
\end{tabular}

¥ The dependent variable in (3) is the non-production wage bill share: $h_{i}^{w} \equiv w_{H, i} H_{i} /\left(w_{H, i} H_{i}+w_{L, i} L_{i}\right)$. Notes: Robust standard errors in parentheses (for (1) - (3) clustered by sector). Key: *** significant at $1 \%$; ** 5\%; *10\%. Regressions (1) and (2) are weighted by sectors' average share in total manufacturing employment 1967-92; (3) by the average share in total manufacturing wage bill 1967-92; (4) and (5) by the sector's employment in 1967 and 1992, respectively. All variables in (1) represent 5-year differences (in this case, $\mathrm{R} \& \mathrm{D}$ intensity is $R \& D_{t}-R \& D_{t-5}$.), while levels are used in the remaining regressions. 
Table 5: Interaction of input skill intensity with input differentiation. Dependent variable is $h_{i t}$.

\begin{tabular}{|c|c|c|c|c|c|}
\hline \multirow[t]{2}{*}{ Input skill measure } & \multicolumn{3}{|c|}{$\sigma_{i}$} & \multirow{2}{*}{$\begin{array}{l}\sigma_{i}^{2 \mathrm{~d}} \\
(4)\end{array}$} & \multirow{2}{*}{$\begin{array}{l}\sigma_{i}^{w} \\
(5)\end{array}$} \\
\hline & (1) & (2) & (3) & & \\
\hline $\begin{array}{l}\text { Input skill intensity }\left(\beta_{1}\right) \text { : } \\
\sigma_{i} / \sigma_{i}^{2 \mathrm{~d}} / \sigma_{i}^{w}\end{array}$ & $\begin{array}{l}.293^{*} \\
(.152)\end{array}$ & $\begin{array}{l}.118 \\
(.154)\end{array}$ & $\begin{array}{l}.046 \\
(.158)\end{array}$ & $\begin{array}{l}-.071 \\
(.240)\end{array}$ & $\begin{array}{l}.018 \\
(.219)\end{array}$ \\
\hline $\begin{array}{l}\text { Inp. skill intensity } \times \text { inp. differentiation }\left(\beta_{2}\right) \text { : } \\
\sigma_{i} \times \kappa_{i} / \sigma_{i}^{2 \mathrm{~d}} \times \kappa_{i} / \sigma_{i}^{w} \times \kappa_{i}\end{array}$ & $\begin{array}{l}1.118^{* * *} \\
(.317)\end{array}$ & $\begin{array}{l}1.147 * * * \\
(.334)\end{array}$ & $\begin{array}{l}1.284 * * * \\
(.312)\end{array}$ & $\begin{array}{l}1.325 * * * \\
(.449)\end{array}$ & $\begin{array}{l}1.213^{* * *} \\
(.389)\end{array}$ \\
\hline Implied coefficient: $\hat{\beta}=\hat{\beta}_{1}+\hat{\beta}_{2} \bar{\kappa}$ & $.907 * * *$ & $.747 * * *$ & $.751 * * *$ & $.657 * * *$ & $.684 * * *$ \\
\hline Controls & no & yes & yes & yes & yes \\
\hline $\begin{array}{l}\text { Sector fixed effects } \\
\text { Time fixed effects }\end{array}$ & $\begin{array}{l}\text { yes } \\
\text { yes }\end{array}$ & $\begin{array}{l}\text { yes } \\
\text { yes }\end{array}$ & $\begin{array}{l}\text { yes } \\
\text { no }\end{array}$ & $\begin{array}{l}\text { yes } \\
\text { yes }\end{array}$ & $\begin{array}{l}\text { yes } \\
\text { yes }\end{array}$ \\
\hline $\begin{array}{l}R^{2} \\
R^{2} \text { (within) } \\
\text { Observations }\end{array}$ & $\begin{array}{l}.97 \\
.53 \\
2148\end{array}$ & $\begin{array}{l}.98 \\
.59 \\
2089\end{array}$ & $\begin{array}{l}.98 \\
.58 \\
2089\end{array}$ & $\begin{array}{l}.98 \\
.58 \\
2083\end{array}$ & $\begin{array}{c}.98 \\
.59 \\
2089\end{array}$ \\
\hline
\end{tabular}

Notes: Clustered standard errors (by sector) in parentheses. Key: *** significant at 1\%;** 5\%;*10\%. All regressions and the mean $\bar{\kappa}$ are weighted by sectors' average share in total manufacturing employment 1967-92. Controls include: Structures per worker $\left(k^{\text {struct }}\right)$, equipment per worker $\left(k^{\text {equip }}\right)$, high-tech capital $(H T / K), R \& D$ intensity $\left(R \& D_{\text {lag }}\right)$, and outsourcing $\left(O S^{\text {narr }}\right)$, as well as their interactions with input differentiation: $k^{\text {struct }} \times \kappa_{i}, k^{\text {equip }} \times \kappa_{i}, H T / K \times \kappa_{i}, R \& D_{\text {lag }} \times$ $\kappa_{i}$, and $O S^{\text {narr }} \times \kappa_{i}$. Weighted average input differentiation is $\bar{\kappa}=.549$. 
Table 6: Contribution to skill upgrading. Dependent variable is the white-collar wage bill share $h_{i t}^{w}$.

\begin{tabular}{|c|c|c|c|c|c|c|c|}
\hline & \multirow[b]{2}{*}{$\begin{array}{l}\text { Change } \\
\text { '67-'92 }\end{array}$} & \multicolumn{2}{|l|}{$(1)$} & \multicolumn{2}{|c|}{ (2) } & \multicolumn{2}{|c|}{ (3) } \\
\hline & & $\begin{array}{l}\text { Regres- } \\
\text { sion }\end{array}$ & $\begin{array}{l}\text { Contri- } \\
\text { bution }\end{array}$ & $\begin{array}{l}\text { Regres- } \\
\text { sion }\end{array}$ & $\begin{array}{l}\text { Contri- } \\
\text { bution }\end{array}$ & $\begin{array}{l}\text { Regres- } \\
\text { sion }\end{array}$ & $\begin{array}{l}\text { Contri- } \\
\text { bution }\end{array}$ \\
\hline $\begin{array}{l}\text { Input skill intensity: } \Delta \sigma_{i} \\
\text { instrumented }\end{array}$ & .0546 & & & $\begin{array}{l}.485^{* * *} \\
(.098)\end{array}$ & $36.4 \%$ & $\begin{array}{l}.499 * * * \\
(.093)\end{array}$ & $37.5 \%$ \\
\hline Structures per worker: $\triangle k^{\text {struct }}$ & .0120 & $\begin{array}{l}.281 \\
(.220)\end{array}$ & $4.7 \%$ & $\begin{array}{l}.196 \\
(.140)\end{array}$ & $3.2 \%$ & $\begin{array}{l}.190 \\
(.129)\end{array}$ & $3.1 \%$ \\
\hline Equipment per worker: $\triangle k^{\text {equip }}$ & .0383 & $\begin{array}{l}-.0679 \\
(.110)\end{array}$ & $-3.6 \%$ & $\begin{array}{l}-.0858 \\
(.082)\end{array}$ & $-4.5 \%$ & $\begin{array}{l}-.0741 \\
(.070)\end{array}$ & $-3.9 \%$ \\
\hline $\begin{array}{l}\text { High-Tech capital: } \triangle H T / K \\
\quad \text { instrumented in (3) }\end{array}$ & .0469 & $\begin{array}{l}.189^{*} \\
(.115)\end{array}$ & $12.2 \%$ & $\begin{array}{l}.299 * * * \\
(.097)\end{array}$ & $19.3 \%$ & $\begin{array}{l}.423 * * \\
(.190)\end{array}$ & $27.3 \%$ \\
\hline $\begin{array}{l}\text { R\&D intensity } \triangle R \& D \\
\quad \text { instrumented in (3) }\end{array}$ & .0108 & $\begin{array}{l}.442 * * * \\
(.164)\end{array}$ & $6.6 \%$ & $\begin{array}{l}.221 \\
(.134)\end{array}$ & $3.3 \%$ & $\begin{array}{l}.26 \\
(.242)\end{array}$ & $3.9 \%$ \\
\hline Outsourcing: $\triangle O S^{\text {narr }}$ & .0470 & $\begin{array}{l}.103 * * \\
(.043)\end{array}$ & $6.7 \%$ & $\begin{array}{l}.0838 * * \\
(.037)\end{array}$ & $5.4 \%$ & $\begin{array}{l}.0816^{* *} \\
(.038)\end{array}$ & $5.3 \%$ \\
\hline Outs.: $\triangle\left(O S^{\text {broad }}-O S^{\text {narr }}\right)$ & .0571 & $\begin{array}{l}.136 * * * \\
(.047)\end{array}$ & $10.7 \%$ & $\begin{array}{l}.0508 \\
(.056)\end{array}$ & $4.0 \%$ & $\begin{array}{l}.0358 \\
(.049)\end{array}$ & $2.8 \%$ \\
\hline Total Contribution: & & & $37.2 \%$ & & $67.1 \%$ & & $75.9 \%$ \\
\hline \multicolumn{2}{|l|}{ Real shipments: $\triangle \ln (Y)$} & \multicolumn{2}{|l|}{$\begin{array}{l}-.012 * \\
(.007)\end{array}$} & \multicolumn{2}{|l|}{$\begin{array}{l}-.012 * * * \\
(.004)\end{array}$} & \multicolumn{2}{|l|}{$\begin{array}{l}-.010 * * \\
(.005)\end{array}$} \\
\hline \multicolumn{2}{|l|}{ Relative wage: $\triangle \ln \left(w_{H} / w_{L}\right)$} & \multicolumn{2}{|l|}{$\begin{array}{l}.101 * * * \\
(.015)\end{array}$} & \multicolumn{2}{|l|}{$\begin{array}{l}.118 * * * \\
(.012)\end{array}$} & \multicolumn{2}{|l|}{$\begin{array}{l}.115^{* * * *} \\
(.012)\end{array}$} \\
\hline \multicolumn{2}{|l|}{ Observations } & \multicolumn{2}{|l|}{1731} & \multicolumn{2}{|l|}{1402} & \multicolumn{2}{|l|}{1402} \\
\hline \multicolumn{8}{|l|}{ First stage regressions: ${ }^{\ddagger}$} \\
\hline \multicolumn{4}{|c|}{$\begin{array}{l}F \text {-test for significance of IV for } \sigma_{i} \\
\text { Instrumented control variables: } \\
\text { individual } F \text {-test for IV }\end{array}$} & \multicolumn{2}{|l|}{43.6} & \multicolumn{2}{|c|}{$\begin{array}{l}35.4 \\
H T / K, R \& D \\
51.5,15.3\end{array}$} \\
\hline
\end{tabular}

Notes: The first column gives the change of each variable's weighted (by industry wage bill) average over the period 1967-92. The change in the dependent variable $h^{w}$ is .0727 . All regressions are run in 5-year changes and are weighted by sectors' average share in the manufacturing wage bill 1967-92. Standard errors (in parentheses) are robust to arbitrary heteroskedasticity and intra-sector correlation. Key: *** significant at 1\%;** 5\%;*10\%. Regressions (2) and (3) are estimated using two-step feasible efficient GMM. 'Contribution' gives the proportion of the observed change in $h^{w}$ explained by the respective variable. ${ }^{\ddagger}$ Instruments are the 5- and 10-year lags of each instrumented variable. In addition, $\triangle \sigma_{i}$ is instrumented with the 5-year lag of $\triangle \mathbb{T}_{j \neq i}$ (see text). $\triangle R \& D$ also uses its 15 -year lag. 